medRxiv preprint doi: https://doi.org/10.1101/2022.02.04.22270165; this version posted February 6, 2022. The copyright holder for this preprint (which was not certified by peer review) is the author/funder, who has granted medRxiv a license to display the preprint in It is made available under a CC-BY 4.0 International license .

\title{
Using multiple sampling strategies to estimate SARS-CoV-2 epidemiological parameters from genomic sequencing data
}

\section{AUTHOR LIST AND AFFILIATIONS}

\author{
Rhys P. D. Inward ${ }^{1,6}$, Kris V. Parag ${ }^{2,3,5,6}$, Nuno R. Faria ${ }^{1,2,4,5,6}$
}

1. Department of Zoology, University of Oxford, Oxford, UK

2. MRC Centre of Global Infectious Disease Analysis, Jameel Institute for Disease and Emergency Analytics, Imperial College London, London, UK

3. NIHR Health Protection Research Unit in Behavioural Science and Evaluation, University of Bristol, Bristol, UK

4. Instituto de Medicina Tropical, Faculdade de Medicina da Universidade de Sao Paulo, Sao Paulo, Brazil

5. Jointly supervised this work

6. Corresponding author: E-mail: rhys.inward@zoo.ox.ac.uk, k.parag@imperial.ac.uk, n.faria@imperial.ac.uk 
medRxiv preprint doi: https://doi.org/10.1101/2022.02.04.22270165; this version posted February 6, 2022. The copyright holder for this preprint (which was not certified by peer review) is the author/funder, who has granted medRxiv a license to display the preprint in It is made available under a CC-BY 4.0 International license.

\section{ABSTRACT}

SARS-CoV-2 virus genomes are currently being sequenced at an unprecedented pace. The choice of sequences used in genetic and epidemiological analysis is important as it can induce biases that detract from the value of these rich datasets. This raises questions about how a set of sequences should be chosen for analysis, and which epidemiological parameters derived from genomic data are sensitive or robust to changes in sampling. We provide initial insights on these largely understudied problems using SARS-CoV-2 genomic sequences from Hong Kong and the Amazonas State, Brazil. We consider sampling schemes that select sequences uniformly, in proportion or reciprocally with case incidence and which simply use all available sequences (unsampled). We apply Birth-Death Skyline and Skygrowth methods to estimate the time-varying reproduction number $\left(R_{t}\right)$ and growth rate $\left(r_{t}\right)$ under these strategies as well as related $R_{0}$ and date of origin parameters. We compare these to estimates from case data derived from EpiFilter, which we use as a reference for assessing bias. We find that both $R_{t}$ and $r_{t}$ are sensitive to changes in sampling whilst $R_{0}$ and date of origin are relatively robust. Moreover, we find that the unsampled datasets (opportunistic sampling) provided, overall, the worst $R_{t}$ and $r_{t}$ estimates for both Hong Kong and the Amazonas case studies. We highlight that sampling strategy may be an influential yet neglected component of sequencing analysis pipelines. More targeted attempts at genomic surveillance and epidemic analyses, particularly in resource-poor settings which have a limited genomic capability, are necessary to maximise the informativeness of virus genomic datasets. 
medRxiv preprint doi: https://doi.org/10.1101/2022.02.04.22270165; this version posted February 6, 2022. The copyright holder for this preprint (which was not certified by peer review) is the author/funder, who has granted medRxiv a license to display the preprint in perpetuity.

It is made available under a CC-BY 4.0 International license .

\section{INTRODUCTION}

Severe acute respiratory syndrome coronavirus 2 (SARS-CoV-2) is an enveloped singlestranded zoonotic RNA virus belonging to the Betacoronavirus genus and Coronaviridae family (Gorbalenya et al., 2020). It was first identified in late 2019 in a live food market in Wuhan City, Hubei Province, China (Zhu et al., 2020). Within a month, SARS-CoV-2 had disseminated globally through sustained human-to-human transmission. It was declared a public health emergency of international concern on the 30th of January 2020 by the World Health Organisation (World Health Organisation, 2020). Those infected with SARS-CoV-2 have phenotypically diverse symptoms ranging from mild fever to multiple organ dysfunction syndromes and death (Verity et al., 2020).

Despite the implementation of non-pharmaceutical interventions (NPIs) by many countries to control their epidemics, to date over 300 million SARS-CoV-2 cases and 5.4 million deaths have been reported worldwide (World Health Organisation, 2022). These NPIs can vary within and between countries and include restrictions on international and local travel, school closures, social distancing measures and the isolation of infected individuals and their contacts (European Centre for Disease Prevention and Control, 2020). The key aim of NPIs is to reduce epidemic transmission, often measured by epidemiological parameters such as the time-varying reproduction number $\left(R_{t}\right.$ at time $\left.t\right)$ and growth rate $\left(r_{t}\right)$ (Supplementary Table 1$)$ (Anderson et al., 2020; UK Health Security Agency, 2022). However, there is currently great difficulty in estimating and comparing epidemiological parameters derived from case and death data globally due to disparities in molecular diagnostic surveillance and notification systems between countries. Further, even if data are directly comparable, the choice of epidemiological parameter can implicitly shape insights into how NPIs influence transmission potential (Dushoff and Park, 2021; Parag, Thompson and Donnelly, 2021). As such, there is a need to use alternative data sources, such as genomic data (World Health Organisation, 2021a), to gain improved insights into viral transmission dynamics (Jombart et al., 2014; Duchene et al., 2020).

Phylodynamic analysis of virus genome sequences have increasingly been used for studying emerging infectious diseases, as seen during the current SARS-CoV-2 pandemic (Faria et al., 2021; Nadeau et al., 2021; Romano and Melo, 2021; Volz et al., 2021), recent Ebola virus outbreaks in Western Africa (Dudas et al., 2017) and Zika outbreaks in Brazil and the 
medRxiv preprint doi: https://doi.org/10.1101/2022.02.04.22270165; this version posted February 6, 2022. The copyright holder for this preprint (which was not certified by peer review) is the author/funder, who has granted medRxiv a license to display the preprint in perpetuity.

It is made available under a CC-BY 4.0 International license.

Americas (Faria et al., 2017; Grubaugh et al., 2017). Transmissibility estimates such as the basic reproduction number $\left(R_{0}\right), R_{t}$ and $r_{t}$ can be directly inferred from genomic sequencing data in addition to other epidemiological parameters like the date of origin of a given viral variant which can only be inferred from genomic data. This is of particular importance for variants of concern (VOC), genetic variants with evidence of increased transmissibility, more severe disease, and/ or immune evasion. VOC are typically detected through virus genome sequencing and there is often a limited understanding of their epidemiological characteristics from epidemiological data alone (Harvey et al., 2021). To maximise the use of additional epidemiological information from genomic data, clear guidelines on sampling need to be provided (Lesley et al., 2021).

Currently, SARS-CoV-2 virus genomes from COVID-19 cases are being sequenced at an unprecedented pace providing a wealth of virus genomic datasets (Rambaut et al., 2020). There are currently over 7.4 million genomic sequences available on GISAID, an opensource repository for influenza and SARS-CoV-2 genomic sequences (Shu and McCauley, 2017). These rich datasets can be used to provide an independent perspective and can help validate or challenge parameters derived from epidemiological data. Moreover, the use of genomic data can overcome some of the limitations and biases of using epidemiological data alone. For example, it is less susceptible to changes at the government level such as alterations to the definition of a confirmed case and changes to notification systems (de Souza et al., 2020; Tsang et al., 2020). Inferences from virus genomic data improve our understanding of underlying epidemic spread and can facilitate better-informed infection control decisions (Dolan, Whitfield and Andino, 2018).

The most popular approaches used to investigate changes in virus population dynamics include the Bayesian Skyline Plot (Drummond et al., 2005) and Skygrid (Gill et al., 2013) models and the birth-death skyline (BDSKY) (Stadler et al., 2013). These integrate Markov Chain Monte Carlo (MCMC) procedures and often converge slowly on large datasets (Hall, Woolhouse and Rambaut, 2016). As such, currently available SARS-CoV-2 datasets containing thousands of sequences become computationally impractical to analyse and subsampling is necessary. Although there have been some previous studies (Stack et al., 2010; de Silva, Ferguson and Fraser, 2012; Hall, Woolhouse and Rambaut, 2016; Karcher et al., 2016; Parag, du Plessis and Pybus, 2020), the effects of sampling strategies on phylogenetic and phylodynamic inferences of pathogens is currently a neglected area of study (Frost et al., 
medRxiv preprint doi: https://doi.org/10.1101/2022.02.04.22270165; this version posted February 6, 2022. The copyright holder for this preprint (which was not certified by peer review) is the author/funder, who has granted medRxiv a license to display the preprint in It is made available under a CC-BY 4.0 International license.

2015), particularly concerning SARS-CoV-2. To our knowledge, there are no published studies concerning SARS-CoV-2 which explore the effect that sampling strategies have on the phylodynamic reconstruction of key transmission parameters. This is important as incorrectly implementing a sampling scheme or ignoring its importance can mislead inferences and introduce biases (Hall, Woolhouse and Rambaut, 2016; Hidano and Gates, 2019). This raises the important question of how a set of sequences should be selected for analysis and which parameters are sensitive or robust to changes in sampling.

Here we aim to explore how diverse sampling strategies in genomic sequencing may affect the estimation of key epidemiological parameters from genomic data. To do this, we estimate $R_{0}, R_{t}$, and $r_{t}$ from genomic sequencing data under different sampling strategies from a location with high genomic coverage represented by Hong Kong, and a location with low genomic coverage represented by the Amazonas region, Brazil. Moreover, we compare epidemiological parameters derived from genomic data to those estimated from corresponding epidemiological data which we considered here as our gold standard. By getting genomic inferences close to the case data we can then draw better inferences of transmission estimates and parameters that cannot be derived from case data alone. This will help us to understand the impact that sampling strategies have on phylodynamic inference and aid in the interpretation of epidemiological parameters from areas with differing genomic coverage. 
medRxiv preprint doi: https://doi.org/10.1101/2022.02.04.22270165; this version posted February 6, 2022. The copyright holder for this preprint (which was not certified by peer review) is the author/funder, who has granted medRxiv a license to display the preprint in perpetuity.

It is made available under a CC-BY 4.0 International license.

\section{METHODS}

\section{Empirical Estimation of the Reproduction Number, Time-varying Effective Reproduction Number, and Growth Rate}

\section{Epidemiological Datasets}

Two sources of data from the Amazonas region, Brazil and one source of data from Hong Kong were used in calculating empirical epidemiological parameters. For the Amazonas region, mortality, and case data from the SIVEP-Gripe (Sistema de Informação de Vigilância Epidemiológica da Gripe) SARI (severe acute respiratory infections) database, including both class 4 and 5 death records (corresponding to confirmed and suspected COVID-19 deaths), from the $30^{\text {th }}$ of November 2020 up to $7^{\text {th }}$ of February 2021, were used. Here we were interested in cases caused by the P.1/Gamma VOC first detected in Manaus, the number of P.1 cases was calculated by using the proportion of P.1/Gamma viral sequences uploaded to GISAID within each week (Supplementary Figure 1). For Hong Kong, all case and mortality data were extracted from the Centre of Health Protection, Department of Health, the Government of the Hong Kong Special Administrative region up to the $7^{\text {th }}$ of May 2020. Due to lags in the development of detectable viral loads, symptom onset and subsequent testing (Gostic et al., 2020); the date in which each case was recorded was left shifted by 5 days within our models (Pullano et al., 2021) to account for these delays in both datasets.

\section{Basic Reproduction Number}

The $\mathrm{R}_{0}$ was estimated using a time series of confirmed SARS-CoV-2 cases from both Hong Kong and the Amazonas region. To avoid the impact of NPIs on $\mathrm{R}_{0}$ estimates, only data up to the banning of mass gathering in Hong Kong (27 $7^{\text {th }}$ March 2020) and up to the imposition of strict restrictions in the Amazonas region (12 ${ }^{\text {th }}$ January 2021) were used. Weekly counts of confirmed cases were modelled using maximum likelihood methods. The weekly case counts were assumed to be Poisson distributed and were fitted to a deterministic closed SusceptibleExposed-Infectious-Recovered (SEIR) model (Equation 1) by maximising the likelihood of observing the data given the model parameters (Table 1).

Equation 1:

$$
\lambda=\frac{\beta(I)}{N} \frac{d S}{d t}=-\lambda S \frac{d E}{d t}=\lambda S-\gamma E \frac{d I}{d t}=\gamma E-\sigma I \frac{d R}{d t}=\sigma I
$$


medRxiv preprint doi: https://doi.org/10.1101/2022.02.04.22270165; this version posted February 6, 2022. The copyright holder for this preprint (which was not certified by peer review) is the author/funder, who has granted medRxiv a license to display the preprint in It is made available under a CC-BY 4.0 International license.

Subsequently, the log-likelihood was used to calculate the $\mathrm{R}_{0}$ by fitting $\beta$, the effective contact rate (Equation 2).

Equation 2:

$$
R_{0}=\beta \alpha
$$

To generate approximate confidence intervals for $R_{0}$, bootstrapping was used with 1000 iterations.

Table 1: This shows the parameter estimates used within the deterministic SEIR model.

\begin{tabular}{|c|c|c|}
\hline Parameter & Description & Value (source) \\
\hline R0 & $\begin{array}{c}\text { Basic Reproduction } \\
\text { Number }\end{array}$ & Estimated \\
\hline \multirow[t]{2}{*}{$\mathrm{N}$} & $\begin{array}{l}\text { Population of Hong } \\
\text { Kong }\end{array}$ & $\begin{array}{l}\text { 7,481,800 persons } \\
\text { (The World Bank, } \\
\text { 2021) }\end{array}$ \\
\hline & $\begin{array}{c}\text { Population of } \\
\text { Amazonas Region }\end{array}$ & $\begin{array}{c}\text { 4,207,714 persons } \\
\text { (IBGE, 2020) }\end{array}$ \\
\hline$\beta$ & $\begin{array}{c}\text { Effective Contact } \\
\text { Rate }\end{array}$ & Estimated \\
\hline$\alpha$ & Infectious Period & $\begin{array}{c}0.07 \text { (Byrne et al., } \\
\text { 2020) }\end{array}$ \\
\hline$\lambda$ & Force of Infection & Estimated \\
\hline$\gamma$ & $\begin{array}{c}\text { Progression from } \mathrm{E} \text { to } \\
\text { I }\end{array}$ & $\begin{array}{c}5.26 \text { day }^{-1} \text { (McAloon } \\
\text { et al., 2020) }\end{array}$ \\
\hline$\delta$ & $\begin{array}{l}\text { Progression from I to } \\
\text { R }\end{array}$ & $\begin{array}{c}14.3 \text { day }^{-1} \text { (Byrne et } \\
\text { al., 2020) }\end{array}$ \\
\hline $\mathrm{S}$ & $\begin{array}{l}\text { Susceptible } \\
\text { compartment }\end{array}$ & Estimated \\
\hline
\end{tabular}




\begin{tabular}{|c|c|c|}
\hline E & $\begin{array}{c}\text { Exposed } \\
\text { Compartment }\end{array}$ & Estimated \\
\hline $\mathrm{I}$ & $\begin{array}{c}\text { Infectious } \\
\text { Compartment }\end{array}$ & Estimated \\
\hline $\mathrm{R}$ & $\begin{array}{c}\text { Recovered } \\
\text { Compartment }\end{array}$ & Estimated \\
\hline
\end{tabular}

\section{Time-varying Effective Reproduction Number}

To estimate the $R_{t}$ from empirical line list data the EpiFilter model (Parag, 2021) was used. To estimate $R_{t}$, EpiFilter uses a renewal transmission model; a general and popular framework used in the modelling of infectious diseases (Fraser, 2007). This model describes how the number of new cases (incidence) at time $t$ depends on the $R_{t}$ at that specified time point and the past incidence, which is summarised by the cumulative number of cases up to each time point weighted by the generation time distribution. Moreover, EpiFliter integrates both Bayesian forward and backward recursive smoothing. This improves $R_{t}$ estimates by leveraging the benefits of two of the most popular $R_{t}$ estimation approaches: EpiEstim (Cori et al., 2013) and the Wallinga-Teunis equation (Wallinga and Teunis, 2004). Both methods only utilise a proportion of the information available with either past or future incidence being informative. EpiFilter combines both past and future information and consequently minimises the mean squared error in estimation and reduces dependence on prior assumptions. We assume the generation time distribution is well approximated by the serial interval (SI) distribution (Flaxman et al., 2020). EpiFilter was used as a reference for parameters estimated from genomic data.

\section{Growth Rate}

After the $R_{t}$ has been inferred, its relationship with $r_{t}$ as described by the Wallinga-Lipsitch equation for a gamma distributed generation time (Equation 3) was used to estimate $r_{t}$ (Wallinga and Lipsitch, 2007). The SI and variance for Hong Kong were derived from a systematic review and meta-analysis exploring these values (Rai, Shukla and Dwivedi, 2021) and a study exploring SI in Brazil was used for the Amazonas datasets (Prete et al., 2021). The SI was assumed to be gamma distributed. The gamma distribution is represented by gamma $=(\varepsilon, \gamma)$. 
medRxiv preprint doi: https://doi.org/10.1101/2022.02.04.22270165; this version posted February 6, 2022. The copyright holder for this preprint (which was not certified by peer review) is the author/funder, who has granted medRxiv a license to display the preprint in perpetuity.

It is made available under a CC-BY 4.0 International license .

Equation 3:

$$
r_{t}=\varepsilon\left(R_{t}^{\left(\frac{1}{\gamma}\right)}-1\right)
$$

\section{SARS-CoV-2 Brazilian Gamma VOC and Hong Kong datasets}

All high-quality, complete SARS-CoV-2 genomes were downloaded from GISAID (Shu and McCauley, 2017) for Hong Kong (up to $7^{\text {th }}$ May 2020) and the Amazonas state, Brazil (from 30th November 2020 up to $7^{\text {th }}$ February 2021). Using the Accession ID of each sequence, all sequences were screened and only sequences previously analysed and published in PubMed, MedRxiv, BioRxiv, virological or Preprint repositories were selected for subsequent analysis. For both datasets, sequence alignment was conducted using MAFFTV.7 (Katoh et al., 2002). The first 130 base pairs (bp) and last $50 \mathrm{bps}$ of the aligned sequences were trimmed to remove potential sequencing artefacts in line with the Nextstrain protocol (Hadfield et al., 2018). Both datasets were then processed using the Nextclade pipeline for quality control (https://clades.nextstrain.org/). Briefly, the Nextclade pipeline examines the completeness, divergence, and ambiguity of bases in each genetic sequence. Only sequences deemed 'good' by the Nextclade pipeline were selected for. Subsequently, all sequences were screened for identity and in the case of identical sequences, for those with the same location, collection date, only one such isolate was used. Moreover, PANGO lineage classification was conducted using the Pangolin (Rambaut et al., 2020) software tool (http://pangolin.cog-uk.io) on sequences from the Amazonas region and only those with the designated P.1/Gamma lineage were selected for (Supplementary Figure 1).

\section{Maximum Likelihood tree reconstruction}

Maximum likelihood phylogenetic trees were reconstructed using IQTREE2 (Minh et al., 2020) for both datasets. A TIM2 model of nucleotide substitution with empirical base frequencies and a proportion of invariant sites was used as selected for by the ModelFinder application (Kalyaanamoorthy et al., 2017) for the Hong Kong dataset. For the Brazilian dataset, a TN model of nucleotide substitution (Tamura and Nei, 1993) with empirical base frequencies was selected for. To assess branch support, the approximate likelihood-ratio test based on the Shimodaira-Hasegawa-like procedure with 1,000 replicates (Anisimova et al., 2011), was used. 
medRxiv preprint doi: https://doi.org/10.1101/2022.02.04.22270165; this version posted February 6, 2022. The copyright holder for this preprint (which was not certified by peer review) is the author/funder, who has granted medRxiv a license to display the preprint in perpetuity.

It is made available under a CC-BY 4.0 International license .

\section{Root-to-tip regression}

To explore the temporal structure of both the Brazilian and Hong Kong dataset, TempEst v.1.5.3 (Rambaut et al., 2016) was used to regress the root-to-tip genetic distances against sampling dates (yyyy-mm-dd). The 'best-fitting' root for the phylogeny was found by maximising the $\mathrm{R}^{2}$ value of the root-to-tip regression. Several sequences showed incongruent genetic diversity and were discarded from subsequent analyses. This resulted in a final dataset of $\mathrm{N}=117$ Hong Kong sequences and $\mathrm{N}=196$ Brazilian sequences. The gradient of the slopes (clock rates) provided by TempEst were used to inform the clock prior in the phylodynamic analysis.

\section{Subsampling for analysis}

Four retrospective sampling schemes were used to select a subsample of Amazonas and Hong Kong sequences. Each sampling period was broken up into weeks with each week being used as an interval according to a temporal sampling scheme (without replacement). This temporal sampling scheme was based on the number of reported cases of SARS-CoV-2.

Temporal sampling schemes explored were:

- Uniform sampling: All weeks have equal probability.

- Proportional sampling: Weeks are chosen with a probability proportional to the value of the number of cases in each epi-week.

- Reciprocal-proportional sampling: Weeks are chosen with a probability proportional to the reciprocal of the number of cases in each epi-week.

- No sampling strategy applied: All sequences were included without a sampling strategy applied.

These sampling schemes were inspired by those recommended by the WHO for practical use in different settings and scenarios (World Health Organisation, 2021b). Proportional sampling is equivalent to representative sampling, uniform sampling is equivalent to fixed sampling whilst the unsampled data includes all sampling strategies. Reciprocal-proportional sampling is not commonly used in practice as was used as a control within this study.

\section{Bayesian Evolutionary Analysis}

Date molecular clock phylogenies were inferred for all sampling strategies applied to the Amazonas and Hong Kong dataset using BEAST v1.10.4 (Suchard et al., 2018) with 
medRxiv preprint doi: https://doi.org/10.1101/2022.02.04.22270165; this version posted February 6, 2022. The copyright holder for this preprint (which was not certified by peer review) is the author/funder, who has granted medRxiv a license to display the preprint in perpetuity.

It is made available under a CC-BY 4.0 International license .

BEAGLE library v3.1.0 (Ayres et al., 2019) for accelerated likelihood evaluation. For both the Amazonas and Hong Kong datasets, a HKY substitution model with gamma-distributed rate variation among sites and four rate categories was used to account for among-site rate variation (Hasegawa, Kishino and Yano, 1985). A strict clock molecular clock model was chosen. Both the Amazonas and Hong Kong dataset were analysed under a flexible nonparametric skygrid tree prior (Hill and Baele, 2019). Four independent MCMC chains were run for both datasets. For the Amazonas dataset, each MCMC chain consisted of 250,000,000 steps with sampling every 50,000 steps. Meanwhile, for the Hong Kong dataset, each MCMC chain consisted of $200,000,000$ steps with sampling every 40,000 steps. For both datasets, the four independent MCMC runs were combined using LogCombiner v1.10.4 (Suchard et al., 2018). Subsequently, $10 \%$ of all trees were discarded as burn in, and the effective sample size of parameter estimates were evaluated using TRACER v1.7.2 (Rambaut et al., 2018). An effective sample size of over 200 was obtained for all parameters. Maximum clade credibility (MCC) trees were summarised using Tree Annotator (Suchard et al., 2018).

\section{Phylodynamic Reconstruction}

Estimation of the Reproduction Number and Time-varying Effective Reproduction Number The Bayesian birth-death skyline (BDSKY) model (Stadler et al., 2013) implemented within BEAST 2 v2.6.5 (Bouckaert et al., 2019) was used to estimate time-varying rates of epidemic transmission, measured as changes in $R_{t}$ (Table 2). A HKY substitution model with a gamma-distributed rate variation among sites and four rate categories (Hasegawa, Kishino and Yano, 1985) was used alongside a strict molecular clock model. A lognormal distribution was used for $R_{t}$. The selected number of intervals for both datasets was 5 , representing $R_{t}$ changing every 2.5 weeks for the Hong Kong datasets and every 2 weeks for the Brazilian datasets, with equidistant intervals per step. An exponential distribution was used with a mean of $36.5 \mathrm{y}^{-1}$ for the rate of becoming infectious, assuming a mean duration of infection of 10 days (Nadeau et al., 2021). A uniform distribution was used for the sampling proportion. Four independent MCMC chains were run for 50 million MCMC steps with sampling every 5000 steps for each dataset. The four independent MCMC runs were combined using LogCombiner v2.6.5. (Bouckaert et al., 2019) and the effective sample size of parameter estimates were evaluated using TRACER v1.7.2 (Rambaut et al., 2018). An effective sample size of over 200 was obtained for all parameters. The bdskytools R package (https://github.com/laduplessis/bdskytools) was used to plot the BDSKY results. 
medRxiv preprint doi: https://doi.org/10.1101/2022.02.04.22270165; this version posted February 6, 2022. The copyright holder for this preprint (which was not certified by peer review) is the author/funder, who has granted medRxiv a license to display the preprint in It is made available under a CC-BY 4.0 International license.

Table 2: Values and priors for the parameters of the BDSKY model

\begin{tabular}{|c|c|c|c|}
\hline Parameter & Dataset & Value or prior & Rationale/Assumption \\
\hline \multirow{2}{*}{ Clock rate } & Brazil & $\begin{array}{c}4.0 \times 10^{-4} \\
\text { (subs/site/year) }\end{array}$ & \multirow{2}{*}{$\begin{array}{l}\text { Informed by root-to-tip } \\
\text { regression }\end{array}$} \\
\hline & Hong Kong & $\begin{array}{c}1.0 \times 10^{-4} \\
\text { (subs/site/year) }\end{array}$ & \\
\hline Death rate & $\begin{array}{c}\text { Brazil and Hong } \\
\text { Kong }\end{array}$ & $36.5 \mathrm{y}^{-1}$ & $\begin{array}{l}\text { The period between } \\
\text { infection and becoming } \\
\text { uninfectious assumed an } \\
\text { exponential distribution } \\
\text { with a mean of } 10 \mathrm{~d} \\
\text { (Nadeau et al., 2021) }\end{array}$ \\
\hline Reproductive number & $\begin{array}{c}\text { Brazil and Hong } \\
\text { Kong }\end{array}$ & $\begin{array}{c}\text { Lognormal }(0.8, \\
0.5)\end{array}$ & $\begin{array}{c}\text { Median } 2.2,95 \% \text { IQR } 0.8 \\
\text { to } 5.9\end{array}$ \\
\hline \multirow{2}{*}{ Time of origin } & Brazil & $\begin{array}{l}\text { Lognormal }(-1.50, \\
0.4) \text { y before } \\
\text { present }\end{array}$ & $\begin{array}{l}\text { Median } 4^{\text {th }} \text { December } \\
2020,95 \% \text { IQR } 25^{\text {th }} \\
\text { September } 2020 \text { to } 12^{\text {th }} \\
\text { January, } 2021\end{array}$ \\
\hline & Hong Kong & $\begin{array}{l}\text { Lognormal }(-1.75 \\
\text { 0.4) y before } \\
\text { present }\end{array}$ & $\begin{array}{c}\text { Median } 18^{\text {th }} \text { January } \\
2020,95 \% \text { IQR } 17^{\text {th }} \\
\text { November } 2019 \text { to } 15^{\text {th }} \\
\text { February } 2020\end{array}$ \\
\hline Sampling proportion & Brazil & Uniform $(0,0.024)$ & $\begin{array}{c}196 \text { sequences from } 8246 \\
\text { suspected P.1 cases as of } \\
7^{\text {th }} \text { February, } 2021\end{array}$ \\
\hline
\end{tabular}


medRxiv preprint doi: https://doi.org/10.1101/2022.02.04.22270165; this version posted February 6, 2022. The copyright holder for this preprint (which was not certified by peer review) is the author/funder, who has granted medRxiv a license to display the preprint in perpetuity

It is made available under a CC-BY 4.0 International license .

\begin{tabular}{|l|c|c|c|}
\hline & Hong Kong & Uniform (0, 0.116) & $\begin{array}{c}117 \text { sequences from 1012 } \\
\text { confirmed cases as of } 7^{\text {th }} \\
\text { May, 2020 }\end{array}$ \\
\hline
\end{tabular}

\section{Estimation of Growth Rates}

For each dataset, a scaled proxy for $r_{t}$ was estimated through time using the skygrowth model (Volz and Didelot, 2018) within R. Skygrowth uses MCMC to apply a first-order autoregressive stochastic process, founded on a non-parametric Bayesian approach, on the growth rate of the effective population size. The MCMC chains were run for one million iterations for each dataset on their MCC tree with an Exponential $\left(10^{-5}\right)$ prior on the smoothing parameter. The skygrowth model was parameterised assuming that the effective population size of SARS-COV-2 could change every two weeks. To enable comparisons of $r_{t}$ estimated by skygrowth and $r_{t}$ estimated by EpiFilter, the $r_{t}$ provided by the skygrowth model was converted to the exponential growth rate. To do this, the $R_{t}$ was calculated from $r_{t}$ by adding a gamma rate variable which assumed a mean duration of infection of 10 days (Nadeau et al., 2021). Subsequently, the Wallinga-Lipsitch equation (Equation 3) was used to convert $R_{t}$ into the exponential growth rate (Wallinga and Lipsitch, 2007).

\section{Comparing Parameters Estimates from Genetic and Epidemiological Data}

To compare parameters estimates from epidemiological and genetic data the Jensen-Shannon divergence ( $D_{\mathrm{JS}}$ ) (Lin, 1991), which measures the similarity between two probability mass functions (PMFs), was applied. The D Js offers a formal information theoretic evaluation of distributions and is more robust than comparing Bayesian credible intervals (BCIs) since it considers both the shape and spread of a given distribution. The $\mathrm{D}_{\mathrm{JS}}$ is essentially a symmetric and smoothed version of the Kullback-Leibler divergence $\left(\mathrm{D}_{\mathrm{KL}}\right)$ and is commonly used in the fields of machine learning and bioinformatics. The $\mathrm{D}_{\mathrm{KL}}$ between two PMFs, $\mathrm{P}$ and $\mathrm{Q}$, is defined as $\mathrm{D}_{\mathrm{KL}}$ in Equation 4 below (Kullback and Leibler, 1951).

Equation 4:

$$
D_{K L}(P \| M)=\sum_{x \in X} P(x) \log \left(\frac{P(x)}{Q(x)}\right)
$$


medRxiv preprint doi: https://doi.org/10.1101/2022.02.04.22270165; this version posted February 6, 2022. The copyright holder for this preprint (which was not certified by peer review) is the author/funder, who has granted medRxiv a license to display the preprint in It is made available under a CC-BY 4.0 International license.

To calculate the PMF for each epidemiological parameter, the cumulative probability density function (PDF) was extracted for each model, converted to a probability density function (PDF), and a discretisation procedure then applied (Equation 5). $\tau$ represents the PDF and is discretized via Equation 4 , where $\mathrm{s}=0.05,0.01 \ldots$ and $\tau(v)$ is the cumulative probability density of $\tau$.

Equation 5:

$$
\tau_{R t, r t, R 0}=\int_{s-0.025}^{s+0.025} \tau(v)
$$

The Jensen-Shannon distance (JSD) metric quantifies the square-root of the total $\mathrm{D}_{\mathrm{JS}}$ to the average probability distribution and is the metric that we used to compare parameter estimations from differing sampling strategies. The DJS can be calculated using Equation 6 with $\mathrm{P}$ and $\mathrm{Q}$ representing the two probability distributions and $\mathrm{D}_{\mathrm{KL}}$ as the KL divergence. A smaller JSD metric indicates that P and Q are more similar with a Jensen-Shannon distance of 0 indicating equivalence of the two distributions. The mean JSD was taken over all intervals for the BDSKY and Skygrowth models to obtain an overall measure of the level of estimated similarity.

Equation 6:

$$
D_{J S}(P \| Q)=\frac{1}{2} D_{K L}(P \| M)+\frac{1}{2} D_{K L}(Q \| M) \text { where } M=\frac{1}{2}(P+Q)
$$


medRxiv preprint doi: https://doi.org/10.1101/2022.02.04.22270165; this version posted February 6, 2022. The copyright holder for this preprint (which was not certified by peer review) is the author/funder, who has granted medRxiv a license to display the preprint in It is made available under a CC-BY 4.0 International license.

\section{RESULTS}

\section{Sampling Schemes}

\section{Hong Kong}

Hong Kong reacted rapidly upon learning of the emergence of SARS-CoV-2 in Wuhan, Hubei province, China by declaring a state of emergency on the 25th of January 2020 and by mobilising intensive surveillance schemes in response to initial cases (Cowling et al., 2020). This appeared to be successful in controlling the first wave of cases. However, due to imported cases from Europe and North America, a second wave of SARS-CoV-2 infections emerged prompting stricter NPIs such as the closure of borders and restrictions on gatherings (Cowling et al., 2020). Following these measures, the incidence of SARS-CoV-2 rapidly decreased (Figure 1). Hong Kong has a high sampling intensity with $11.6 \%$ of confirmed cases sequenced during our study period.

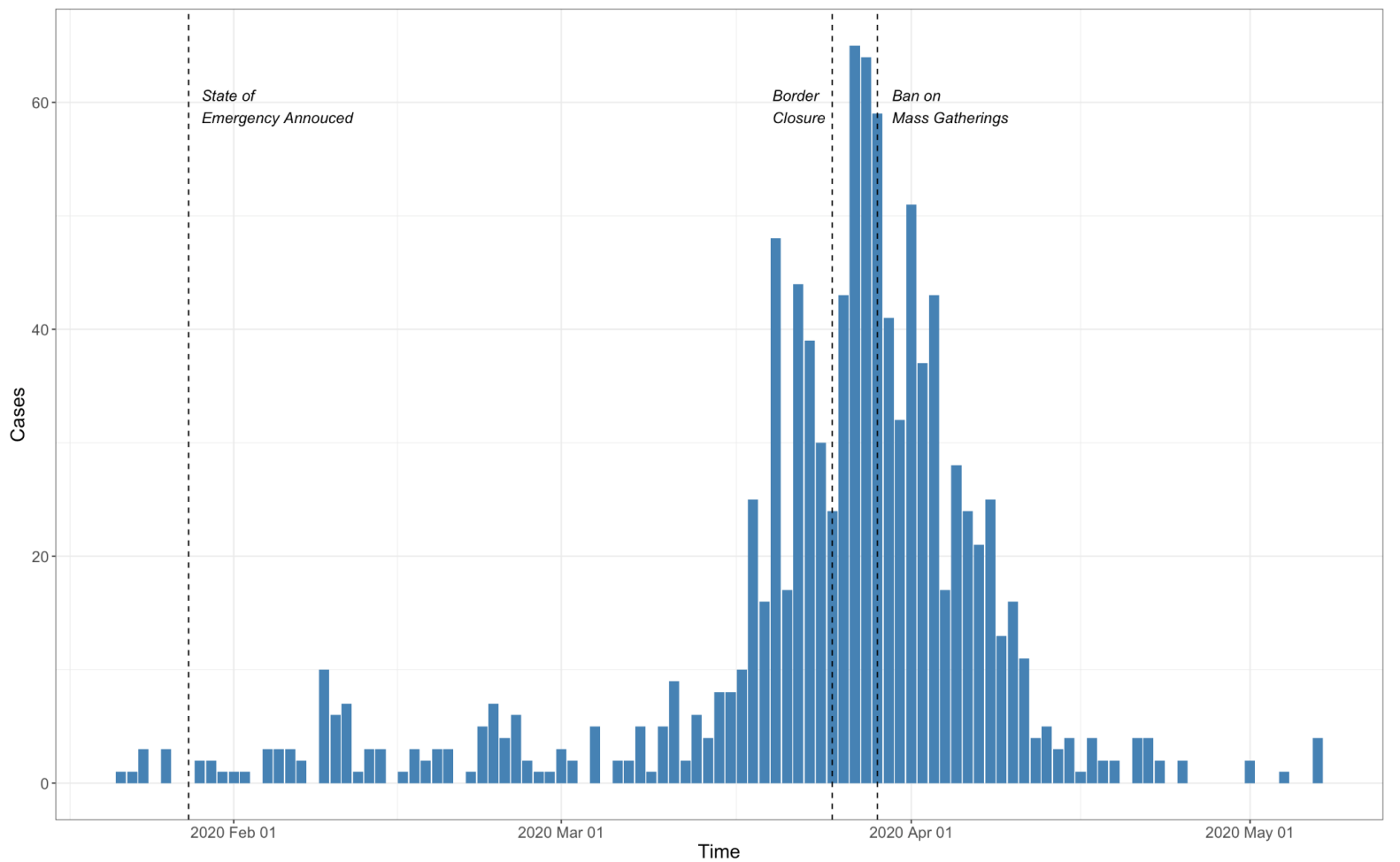

Figure 1: Confirmed SARS-CoV-2 cases from Hong Kong until $7^{\text {th }}$ of May 2020. The dashed lines represent policy change-times (Cowling et al., 2020).

The number of cases within Hong Kong for each week was used to inform the sampling schemes used within this study. This resulted in the unsampled scheme having $\mathrm{N}=117$ sequences, the proportional sampling scheme having $\mathrm{N}=54$ sequences, the uniform sampling 
medRxiv preprint doi: https://doi.org/10.1101/2022.02.04.22270165; this version posted February 6, 2022. The copyright holder for this preprint (which was not certified by peer review) is the author/funder, who has granted medRxiv a license to display the preprint in It is made available under a CC-BY 4.0 International license.

scheme having $\mathrm{N}=79$ and the reciprocal-proportional sampling scheme having $\mathrm{N}=84$ sequences (Supplementary Figure 2).

\section{Amazonas}

The Amazonas state of Brazil had its first laboratory confirmed case of SARS-CoV-2 in March 2020 in a traveller returning from Europe (Nascimento et al., 2020). The first wave of SARS-CoV-2 infections within the state peaked in early May 2020 (Figure 2). From then, the epidemic waned, cases dropped, remaining stable until mid-December 2020. The number of cases then started growing exponentially, ushering in a second epidemic wave. This second wave peaked in January 2021 (Figure 2) and was caused by the emergence of a new SARSCoV-2 VOC, designated P.1/Gamma (Faria et al., 2021).

To combat this second wave, the Government of the Amazonas state suspended all nonessential commercial activities on the 23rd of December 2020 (http://www.pge.am.gov.br/legislacao-covid-19/). However, in response to protests, these restrictions were reversed, and cases continued to climb. On the 12th of January, NPIs were re-introduced (http://www.pge.am.gov.br/legislacao-covid-19/) which seemed to be successful in reducing the case incidence in the state. However, cases remain comparatively high (Figure 2). Amazonas has a low sampling intensity with $2.4 \%$ of suspected P.1/gamma cases sequenced during our study period. 


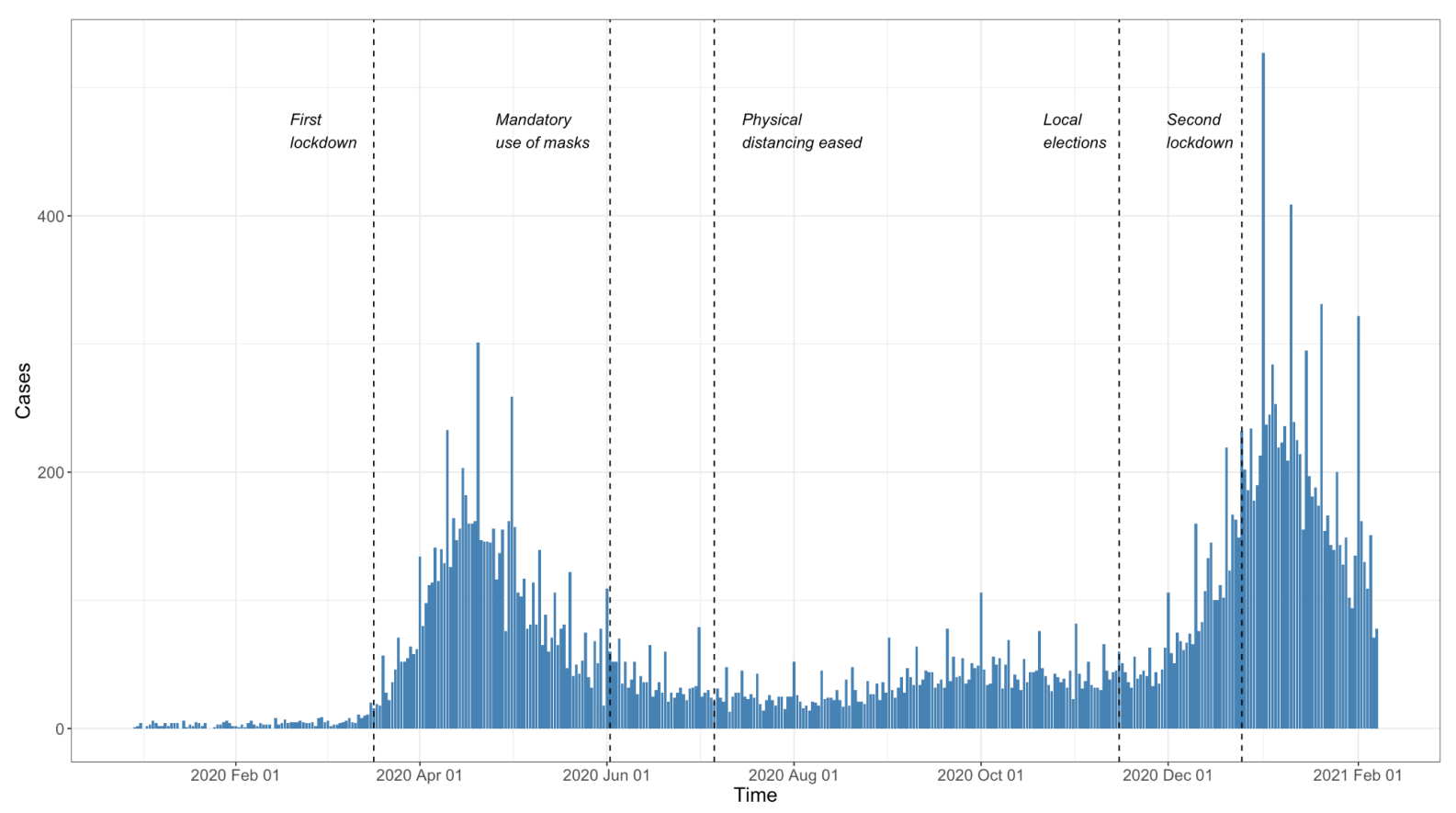

Figure 2: Confirmed SARS-CoV-2 cases from Amazonas state, north Brazil until $7^{\text {th }}$ of February 2021. The dashed lines represent policy change-times (Sabino et al., 2021).

The number of cases within the Amazonas region informed the sampling schemes used within this study. This resulted in the unsampled scheme having $\mathrm{N}=196$ sequences, the proportional sampling scheme having $\mathrm{N}=168$ sequences, the uniform sampling scheme having $\mathrm{N}=150$ and the reciprocal-proportional sampling scheme having $\mathrm{N}=67$ sequences (Supplementary Figure 3).

\section{Root-to-tip Regression}

The correlation $\left(\mathrm{R}^{2}\right)$ between genetic divergence and sampling dates for the Hong Kong datasets ranged between 0.36 and 0.52 and between 0.13 and 0.20 for the Amazonas datasets. This implies that the Hong Kong datasets have a stronger temporal signal. This is likely due to the Hong Kong datasets have a wider sampling interval (106 days) compared to the Amazonas datasets (69 days). A wider sampling interval can lead to a stronger temporal signal (Drummond et al., 2003). No association between the number of sequences in each sampling scheme and the $\mathrm{R}^{2}$ was found. This implies that the data has a high degree of nonindependence which is an unexpected finding as more independent data should reduce the effects of stochasticity. The gradient (rate) of the regression ranged from $1.24 \times 10^{-3}$ to $1.72 \times 10^{-3} \mathrm{~s} / \mathrm{s} / \mathrm{y}$ for the Hong Kong datasets and $4.41 \times 10^{-4}$ to $5.28 \times 10^{-4} \mathrm{~s} / \mathrm{s} / \mathrm{y}$ for the Amazonas datasets. 
medRxiv preprint doi: https://doi.org/10.1101/2022.02.04.22270165; this version posted February 6, 2022. The copyright holder for this preprint (which was not certified by peer review) is the author/funder, who has granted medRxiv a license to display the preprint in It is made available under a CC-BY 4.0 International license.

\section{Estimation of Evolutionary Parameters}

The mean substitution rate (measured in units of number of substitutions per site per year, $\mathrm{s} / \mathrm{s} / \mathrm{y}$ ) and the time to most common recent ancestor (TMRCA) was estimated in BEAST, for both datasets, and the estimation from all sampling schemes was compared.

\section{Hong Kong}

For Hong Kong, the mean substitution rate per site per year ranged from $9.16 \times 10^{-4}$ to $2.09 \times 10^{-3}$ with sampling schemes all having overlapped BCI (Supplementary table 2; Supplementary Figure 4A). This indicates that the sampling scheme did not have a significant impact on the estimation of the clock rate. Moreover, the clock rate is comparable to estimations from the root-to-tip regression and to early estimations of the mean substitution rate per site per year of SARS-CoV-2 (Duchene et al., 2020).

Molecular clock dating of the Hong Kong dataset indicates that the estimated time of the most common recent ancestor was mid-November 2019 and early January 2020 (mean, 10th December 2019; 95\% BCI interval, 14th November 2019 - 1st January 2020, Figure 3B; Supplementary Table 2). This is around 5 weeks before the first confirmed case which was reported on the 18th of January 2021. Once again, all sampling strategies have overlapped BCIs suggesting that the sampling scheme does not significantly impact the estimation of the TMRCA.

\section{Brazil}

For the P.1 lineage in the Amazonas region, the mean substitution rate ranged from $4.00 \mathrm{x}$ 10-4 to $5.56 \times 10-4$ with all sampling schemes having overlapped BCIs (Figure 3D, Supplementary Table 2; Supplementary Figure 4B). This indicates that sampling strategy does not impact the estimation of the clock rate, supporting findings from the Hong Kong dataset. This supports estimations from the root-to-tip analysis. 
medRxiv preprint doi: https://doi.org/10.1101/2022.02.04.22270165; this version posted February 6, 2022. The copyright holder for this preprint (which was not certified by peer review) is the author/funder, who has granted medRxiv a license to display the preprint in It is made available under a CC-BY 4.0 International license.

Molecular clock dating estimated a TMRCA between mid-September and mid-November (mean, 23rd October 2020; 95\% BCI interval, 16th September 2020 - 18th November 2020, Figure 3D; Supplementary Table 2). This is around five weeks before the date of the first P.1 case identified in Manaus used in our study. All sampling schemes have overlapping BCI supporting the inference form the Hong Kong datasets that TMRCA is robust to sampling.

\section{Estimation of Basic Reproduction Number}

We found that Hong Kong had a significantly lower $R_{0}$ of $2.17(95 \%$ credible interval $(\mathrm{CI})=$ 1.43 - 2.83) when compared to Amazonas which had a $R_{0}$ of $3.67(95 \% \mathrm{CI}=2.83-4.48)$. All sampling schemes for both datasets were characterised by similar $R_{0}$ values (Figure 3 ) indicating that the estimation of $R_{0}$ is robust to changes in sampling scheme.
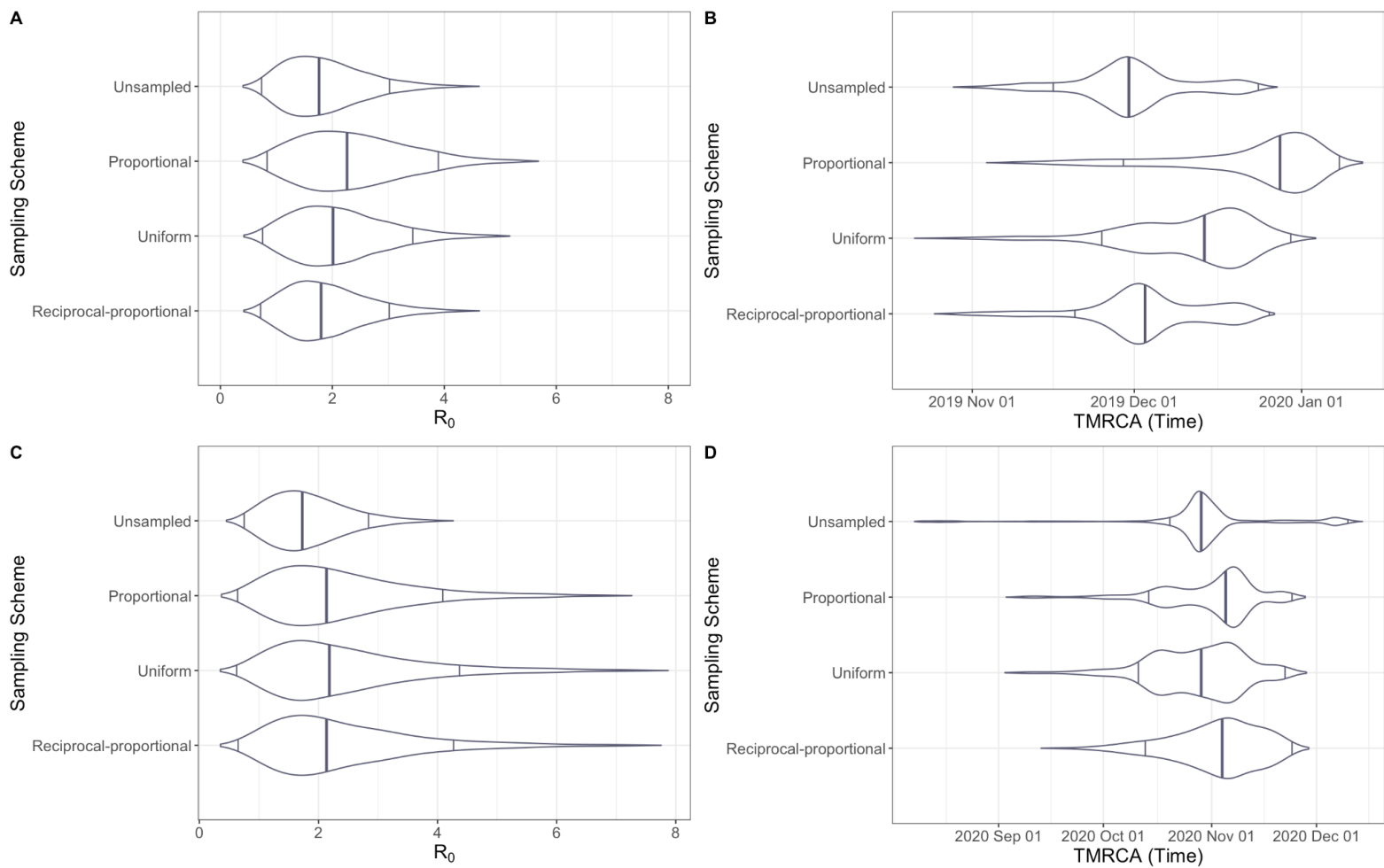

Figure 3: $R_{0}$ estimated from BDSKY and TMRCA for Hong Kong and Brazil. Figure 1A and $\mathrm{B}$ represent Hong Kong and Figure $1 \mathrm{C}$ and D represent the Amazonas. 
medRxiv preprint doi: https://doi.org/10.1101/2022.02.04.22270165; this version posted February 6, 2022. The copyright holder for this preprint (which was not certified by peer review) is the author/funder, who has granted medRxiv a license to display the preprint in It is made available under a CC-BY 4.0 International license.

\section{Time-varying Reproduction number and Growth rate}

We examine the $R_{t}$ and $r_{t}$ estimated for local SARS-CoV-2 epidemics in Hong Kong and Amazonas, Brazil. Our main results showing these two parameters and JSD are in figures 48.

\section{Hong Kong}

The BDSKY model was used alongside the EpiFilter model to estimate the $R_{t}$ for each dataset subsampled according to the different sampling strategies (Figure 4). Based on the proportional sampling scheme, which had the lowest JSD (Figure 4E), we initially infer a super-critical $R_{t}$ value, with a mean around an $R_{t}$ value of 2 , that appears to fall swiftly in response to the state of emergency and the rapid implementation of NPIs. A steady transmission rate subsequently persisted throughout the following weeks around the critical threshold $\left(R_{t}=1\right)$. This period is succeeded by a sharp increase in $R_{t}$, peaking at a mean $R_{t}$ value of 2.6. This is likely due to imported cases from North America and Europe (Cowling et al., 2020). This led to a ban on international travel resulting in a sharp decline in $R_{t}$ (Figure 2). However, this decline lasted around a week with the mean $R_{t}$ briefly increasing until more stringent NPIs such as the banning of major gatherings were implemented. Following this, the $R_{t}$ continued its sharp decline falling below the critical threshold, with transmission becoming sub-critical (Figure 4). 
medRxiv preprint doi: https://doi.org/10.1101/2022.02.04.22270165; this version posted February 6, 2022. The copyright holder for this preprint (which was not certified by peer review) is the author/funder, who has granted medRxiv a license to display the preprint in perpetuity.

It is made available under a CC-BY 4.0 International license .
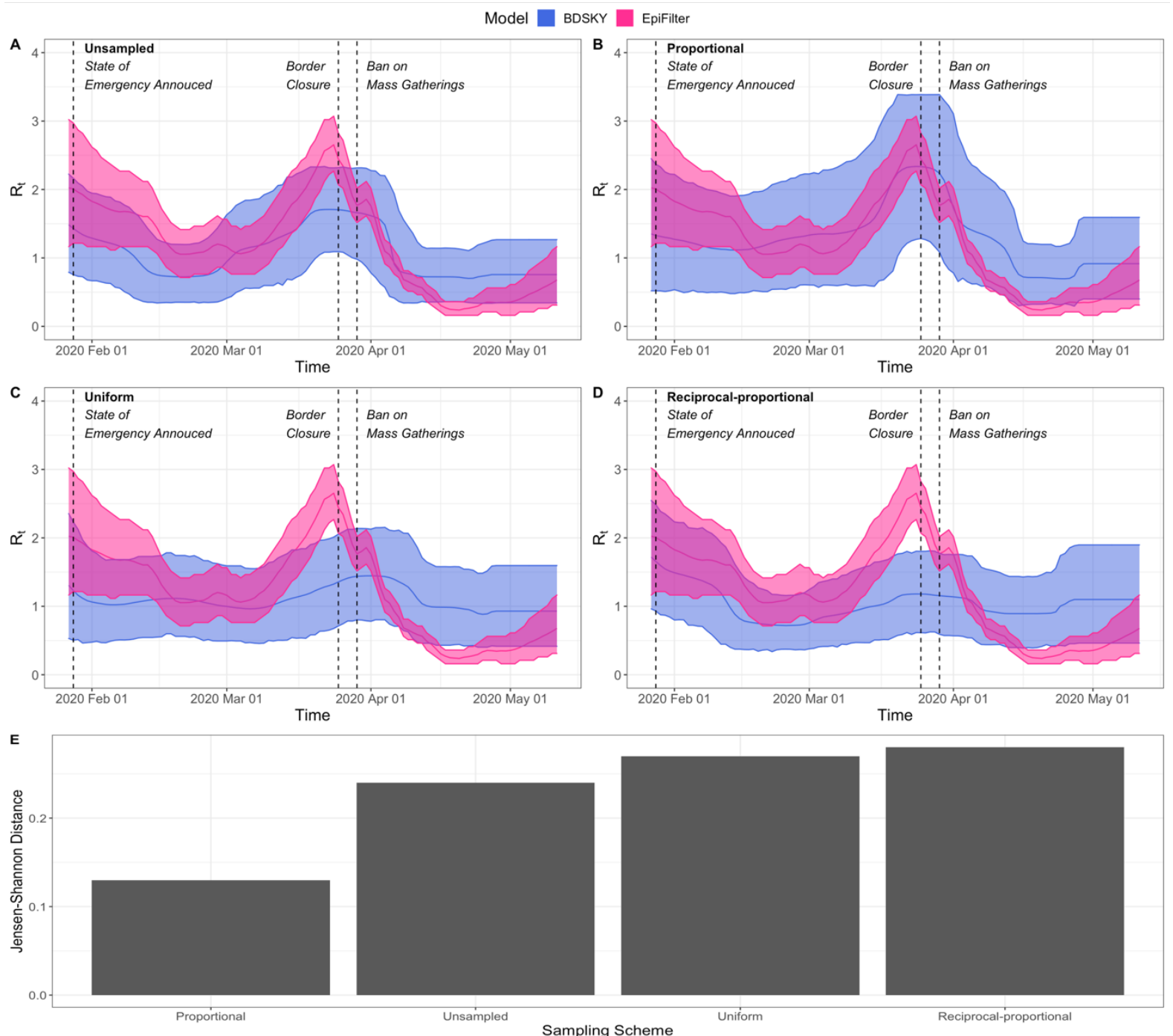

Figure 4: $R_{t}$ estimated from both the BDSKY and EpiFilter models and Jensen Shannon Distance for Hong Kong. The bold writing represents the sampling scheme used in figure A-D. The light-shaded area represents the 95\% HPDI with the darker-shaded area presenting where the BDSKY and EpiFilter models overlap. The solid line represents the mean $R_{t}$ with EpiFilter being represented by a red line and BDSKY a blue line. The dashed lines represent policy change-times. The Jensen Shannon Distance is ordered from best to worse.

These results were mirrored in the estimation of $r_{t .}$. (Figure 5) for which the uniform and proportional sampling schemes showed the least divergence (Figure 5E). There was an initial decline in the $r_{t}$, which steadied at a value of $\sim 0$, indicating that epidemic stabilisation has occurred. This stable period is followed by an increase in $r_{t}$ peaking at around a $5 \%$ increase in case incidence per day (Figure 5). In response to NPIs, the $r_{t}$ starts to decrease, falling below 0 , indicating a receding epidemic. The rate of this decline peaks at around a $7.5 \%$ reduction in case incidence per day (Figure 5). 
medRxiv preprint doi: https://doi.org/10.1101/2022.02.04.22270165; this version posted February $6,2022$. The copyright holder for this preprint (which was not certified by peer review) is the author/funder, who has granted medRxiv a license to display the preprint in perpetuity.

It is made available under a CC-BY 4.0 International license .

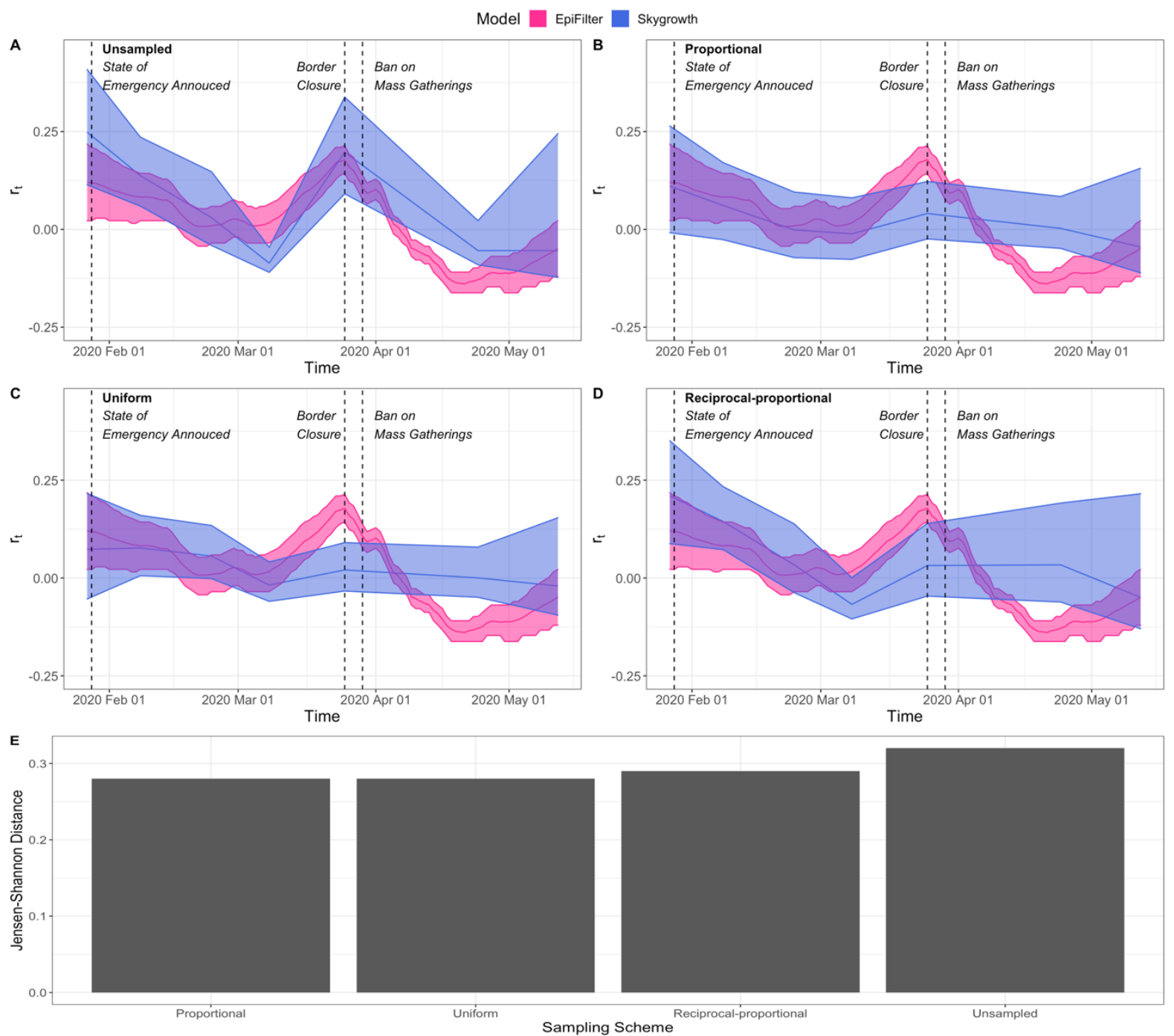

Figure 5: $r_{t}$ estimated from both the Skygrowth and EpiFilter models and Jensen Shannon Distance for Hong Kong. The bold writing represents the sampling scheme used. The lightshaded area represents the 95\% HPDI with the darker-shaded area presenting where the Skygrowth and EpiFilter models overlap. The solid line represents the mean $r_{t}$ with EpiFilter being represented by a red line and Skygrowth a blue line. The dashed lines represent policy change-times. The Jensen Shannon Distance is ordered from best to worse.

\section{Brazil}

Based on the uniform sampling scheme, which had the lowest JSD (Figure 6E), we initially infer a super-critical $R_{t}\left(R_{t}>1\right)$ value with a mean value of $R_{t}=3$ (Figure 6). From this point, the $R_{t}$ declines, although it remains above the critical threshold $\left(R_{t}=1\right)$ for much of the study period. Sub-critical $\left(R_{t}<1\right)$ transmission was only reached after the re-imposition of NPIs. This implies that initial restrictions, such as the suspension of commercial activities, were ineffective in lowering the $R_{t}$ below its critical threshold. Only after more stringent 
medRxiv preprint doi: https://doi.org/10.1101/2022.02.04.22270165; this version posted February 6, 2022. The copyright holder for this preprint (which was not certified by peer review) is the author/funder, who has granted medRxiv a license to display the preprint in perpetuity.

It is made available under a CC-BY 4.0 International license .

restrictions were imposed did $R_{t}$ become sub-critical. However, there is no evidence of a sharp decrease in $R_{t}$ once restrictions were re-imposed, indicating they may have not had a significant impact on $R_{t}$.

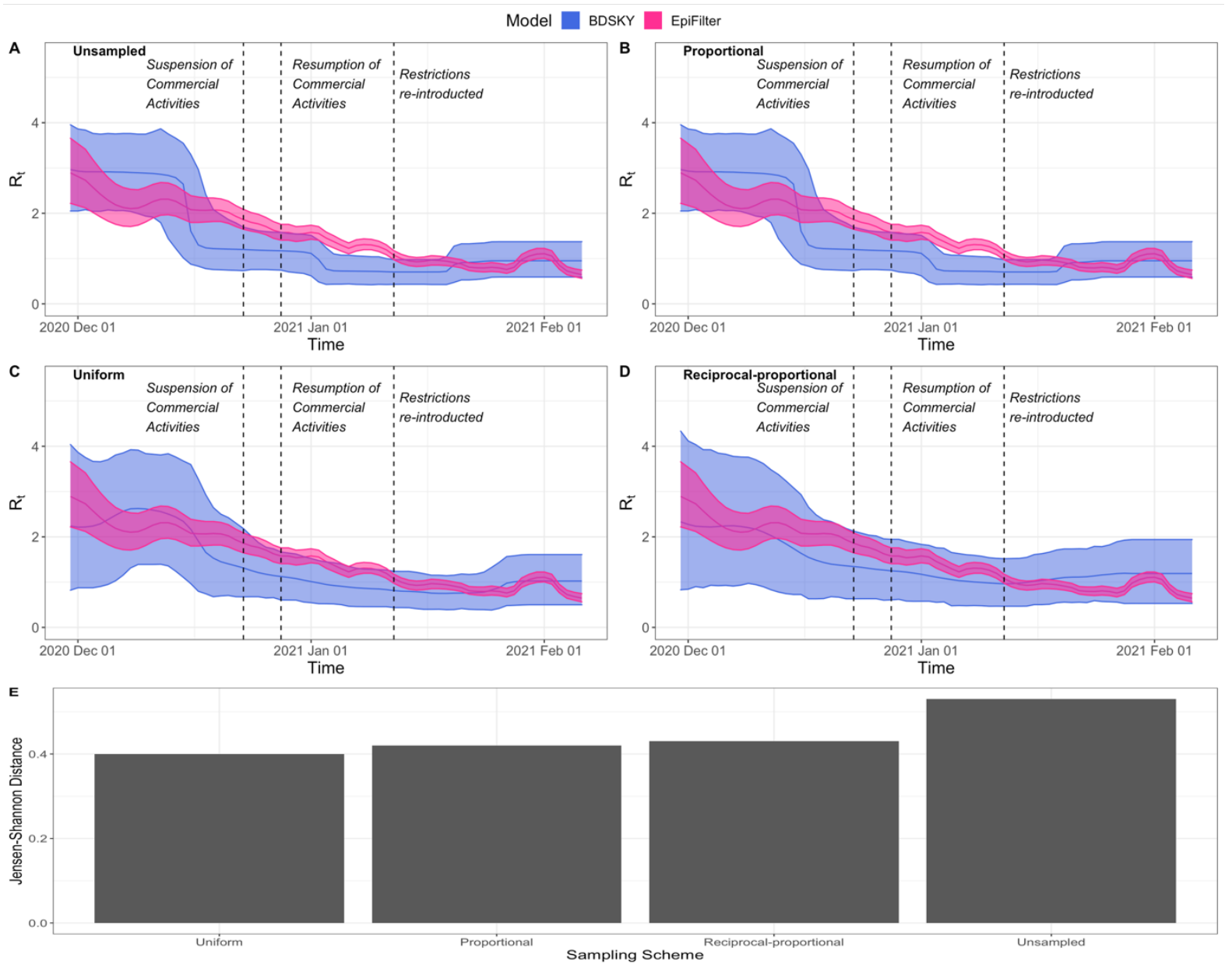

Figure 6: $R_{t}$ estimated from both the BDSKY and EpiFilter models and Jensen Shannon Distance for Amazonas, Brazil. The bold writing represents the sampling scheme used. The light-shaded area represents the $95 \%$ HPDI with the darker-shaded area presenting where the BDSKY and EpiFilter models overlap. The solid line represents the mean $R_{t}$ with EpiFilter being represented by a blue line and BDSKY a red line. The dashed lines represent policy change-times. The Jensen Shannon Distance is ordered from best to worse.

Based on the uniform sampling which had the lowest JSD (Figure 7E) we infer a steady decline in $r_{t}$ which matches the pattern seen with the $R_{t}$ value (Figure 7). The initial $r_{t}$ implied a 23\% mean increase in case incidence per day. Subsequently, the $r_{t}$ falls over the study period. $r_{t}$ falls below 0 after the re-imposition of NPIs with a $3 \%$ reduction in mean case incidence per day by the end of the study period. There is no evidence of any noticeable declines in $r_{t}$ when interventions were introduced indicating that they may have had a minimal impact on the growth rate of P.1/gamma. 
medRxiv preprint doi: https://doi.org/10.1101/2022.02.04.22270165; this version posted February 6, 2022. The copyright holder for this preprint (which was not certified by peer review) is the author/funder, who has granted medRxiv a license to display the preprint in perpetuity.

It is made available under a CC-BY 4.0 International license .
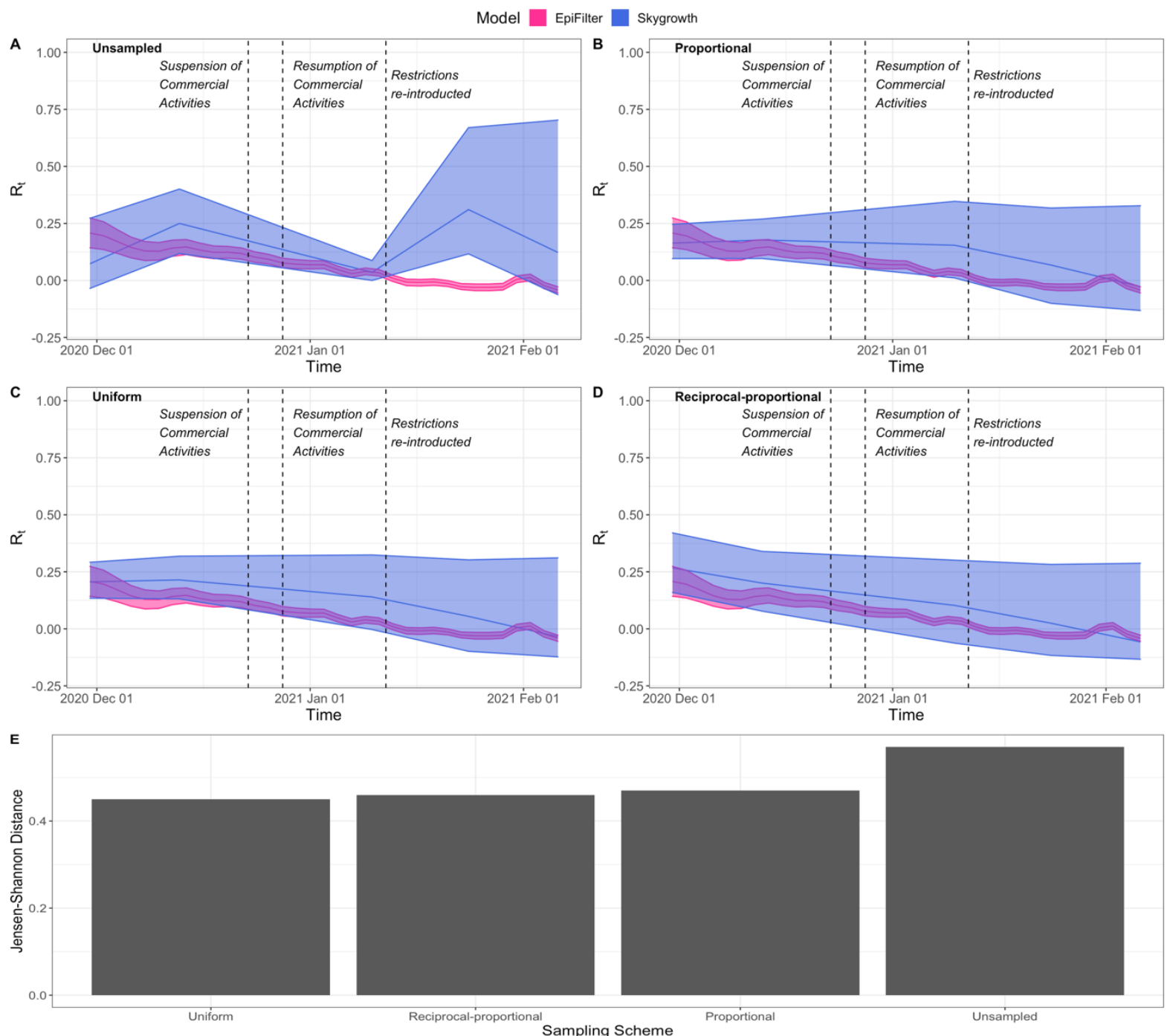

Figure 7: $r_{t}$ estimated from both the Skygrowth and EpiFilter models and Jensen Shannon Distance for Amazonas, Brazil. The bold writing represents the sampling scheme used. The light-shaded area represents the 95\% HPDI with the darker-shaded area presenting where the EpiFilter and Skygrowth models overlap. The solid line represents the mean $r_{t}$ with EpiFilter being represented by a red line and Skygrowth a blue line. The dashed lines represent policy change-times. The Jensen Shannon Distance is ordered from best to worse. 
medRxiv preprint doi: https://doi.org/10.1101/2022.02.04.22270165; this version posted February 6, 2022. The copyright holder for this preprint (which was not certified by peer review) is the author/funder, who has granted medRxiv a license to display the preprint in perpetuity.

It is made available under a CC-BY 4.0 International license.

\section{Discussion}

In this study, phylodynamic methods have been applied to available SARS-CoV-2 sequences from Hong Kong and the Amazonas region of Brazil to infer their relevant epidemiological parameters and to compare the impact that various sampling strategies have on the phylodynamic reconstruction of these parameters.

We estimated the basic reproductive number of SARS-CoV-2 in Hong Kong to be 2.17 (95\% $\mathrm{CI}=1.43-2.83$ ). This supports previous estimates of the initial $R_{0}$ in Hong Kong (Cowling et al., 2020; Zhao et al., 2020) which estimates $R_{0}$ to be $2.23(95 \% \mathrm{CI}=1.47-3.42)$. For the Amazonas region in Brazil, we estimated the $R_{0}$ to be $3.67(95 \% \mathrm{CI}=2.83-4.48)$. Whilst the population of Amazonas State may not be fully susceptible to P.1/gamma (Faria et al., 2021), this shouldn't affect the comparison between sampling schemes. Comparisons of different sampling schemes have revealed the $R_{0}$ is robust to changes in sampling schemes (Figure $3 \mathrm{~A}$ and $\mathrm{C}$ ).

For the Hong Kong dataset, the proportional sampling scheme was superior to all other sampling schemes in estimating $R_{t}$. It successfully predicted the initial super-critical $R_{t}$, its decline in response to rapid NPIs, and subsequent increase and decline during the second wave of infections (Figure 4B). This was in comparison to the reciprocal-proportional that provided the worst JSD (Figure 4D) and in which the $R_{t}$ remained relatively constant throughout the period. In addition, the proportional sampling scheme, alongside the uniform sampling scheme, best estimated $\mathrm{r}_{\mathrm{t}}$ (Figure $5 \mathrm{~B}$ and $\left.\mathrm{C}\right)$. In contrast, for the Amazonas dataset, the uniform sampling scheme best estimated the $R_{t}$ and was joint best for $r_{t}$ (Figure 6C and Figure 7C). It captured both its initial super-critical $R_{t}$ and high $r_{t}$ alongside their subsequent decline. Our estimations for $R_{t}$ are consistent with previous estimates of P.1 in Amazonas state (Faria et al., 2021). This contrasted with the unsampled data in which the $r_{t}$ increased at the end of the period (Figure 7A). This highlights that unlike $R_{0}$, both $R_{t}$ and $r_{t}$ are sensitive to changes in sampling and that even related epidemiological parameters like $R_{t}$ and $r_{t}$ may require different sampling strategies to optimise inferences.

Molecular clock dating of the Hong Kong and Amazonas dataset has revealed that the date of origin is robust to changes in sampling schemes. For Hong Kong, SARS-CoV-2 likely emerged in mid-December 2019 around 5 weeks before the first reported case on the $22^{\text {nd }}$ of January 2020 (Cowling et al., 2020). The Amazonas dataset revealed that the date of the 
medRxiv preprint doi: https://doi.org/10.1101/2022.02.04.22270165; this version posted February 6, 2022. The copyright holder for this preprint (which was not certified by peer review) is the author/funder, who has granted medRxiv a license to display the preprint in perpetuity.

It is made available under a CC-BY 4.0 International license.

common ancestor of the P.1 lineage emerged around late October 2020, around 5 weeks before the first reported case on the $6^{\text {th }}$ of December (Faria et al., 2021), with all BCI's overlapping for each sampling strategy. Like the molecular clock dating, we found that the molecular clock rate was robust to changes in sampling strategies in both datasets with all sampling strategies having overlapped BCI's (Supplementary Table 2 and Supplementary Figure 4). For the Hong Kong dataset, its clock rate is comparable to early estimations of the mean substitution rate per site per year of SARS-CoV-2 (Duchene et al., 2020). However, the clock rate estimated for the Brazilian dataset is lower than initial $8.00 \times 10^{-4} \mathrm{~s} / \mathrm{s} / \mathrm{y}$ which is used in investigating SARS-CoV-2 (Andersen et al., 2020) and that has been used in previous analyses of P.1 (Naveca et al., 2021). This initial estimation of evolutionary rate was estimated from genomic data taken over a short time span at the beginning of the pandemic introducing a time dependency bias (Ghafari et al., 2022). By using a more appropriate clock rate it can improve tree height and rooting resulting in more robust parameter estimations (Boskova, Stadler and Magnus, 2018).

Treating sampling times as uninformative has been shown to be inferior to including them as dependent on effective population size and other parameters by several previous studies (Hall, Woolhouse and Rambaut, 2016; Karcher et al., 2016; Liu et al., 2020; Parag, du Plessis and Pybus, 2020). Whilst these studies did not consider the estimation of epidemiological parameters, they highlight the potential of systematic biases being introduced into the phylodynamic reconstruction by not using a sampling scheme or by assuming an incorrect model for how sampling schemes introduce information. This was supported by our results as phylodynamic inferences with no sampling strategy applied had the poorest performance for both Hong Kong and the Amazonas region. This implies that sampling has a significant impact on phylodynamic reconstruction, and that exploration of sampling strategies is needed to obtain the most robust parameter estimates.

While our results provide a rigorous underpinning and insight into the dynamics of SARSCoV-2 and the impact of sampling strategies in the Amazonas region and Hong Kong, there are limitations. The Skygrowth and BDSKY models do not explicitly consider imports into their respective regions. This is particularly relevant for Hong Kong as most initial sequences from the region were sequenced from importation events (Adam et al., 2020) which can introduce error into parameter estimation. However, as the epidemic expanded, more 
medRxiv preprint doi: https://doi.org/10.1101/2022.02.04.22270165; this version posted February 6, 2022. The copyright holder for this preprint (which was not certified by peer review) is the author/funder, who has granted medRxiv a license to display the preprint in perpetuity.

It is made available under a CC-BY 4.0 International license .

infections were attributable to autochthonous transmission (Adam et al., 2020), and the risk of error introduced by importation events decreased. Moreover, while sampling strategies can account for temporal variations in genomic sampling fractions there is currently no way to account for non-random sampling approaches in either the BDSKY or Skygrowth models (Vasylyeva et al., 2020). It is unclear how network-based sampling may affect parameter estimates obtained through these models (Volz, Koelle and Bedford, 2013) presenting a key challenge in molecular and genetic epidemiology. Spatial heterogeneities were also not explored within this work. This represents the next key step in understanding the impact of sampling as spatial sampling schemes would allow the reconstruction of the dispersal dynamics and estimation of epidemic overdispersion $(k)$, a key epidemiological parameter.

This work has highlighted the impact and importance that applying temporal sampling strategies can have on phylodynamic reconstruction. Whilst more genomic datasets from a variety of countries and regions with different sampling intensities and proportions are needed to create a more generalisable sampling framework and to dissect any potential cofounders, it has been shown that genomic datasets with no sampling strategy applied can introduce significant uncertainty and biases in the estimation of epidemiological parameters. This finding identifies the need for more targeted attempts at performing genomic surveillance and epidemic analyses particularly in resource-poor settings which have a limited genomic capability.

Role of the Funding Sources: N.R.F. acknowledges support from Wellcome Trust and Royal Society Sir Henry Dale Fellowship (204311/Z/16/Z), Bill and Melinda Gates Foundation (INV-034540) and Medical Research Council-Sao Paulo Research Foundation (FAPESP) CADDE partnership award (MR/S0195/1 and FAPESP 18/14389-0) (https://caddecentre.org). K.V.P. acknowledges support from grant reference MR/R015600/1, jointly funded by the UK Medical Research Council (MRC) and the UK Department for International Development (DFID) and from the NIHR Health Protection Research Unit in Behavioural Science and Evaluation at University of Bristol.

CRediT authorship contribution statement: R.P.D.I, K.V.P and N.R.F conceived and designed the study, R.P.D.I wrote and performed the analyses. R.P.D.I wrote the manuscript which was edited and supervised by K.V.P and N.R.F. All authors have contributed to and approved the manuscript for submission. 
medRxiv preprint doi: https://doi.org/10.1101/2022.02.04.22270165; this version posted February 6, 2022. The copyright holder for this preprint (which was not certified by peer review) is the author/funder, who has granted medRxiv a license to display the preprint in perpetuity.

It is made available under a CC-BY 4.0 International license .

\section{References}

Adam, D.C. et al. (2020) "Clustering and superspreading potential of SARS-CoV-2 infections in Hong Kong,” Nature Medicine, 26(11), pp. 1714-1719. doi:10.1038/s41591020-1092-0.

Andersen, K.G. et al. (2020) "The proximal origin of SARS-CoV-2," Nature Medicine [Preprint]. doi:10.1038/s41591-020-0820-9.

Anderson et al. (2020) "The Royal Society SET-C Reports. Reproduction number (R) and growth rate (r) of the COVID-19 epidemic in the UK: methods of estimation, data sources, causes of heterogeneity, and use as a guide in policy formulation [report unpublished]," The Royal Society, (August), pp. 1-86.

Anisimova, M. et al. (2011) "Survey of branch support methods demonstrates accuracy, power, and robustness of fast likelihood-based approximation schemes," Systematic biology. 2011/05/03, 60(5), pp. 685-699. doi:10.1093/sysbio/syr041.

Ayres, D.L. et al. (2019) "BEAGLE 3: Improved Performance, Scaling, and Usability for a High-Performance Computing Library for Statistical Phylogenetics," Systematic Biology, 68(6), pp. 1052-1061. doi:10.1093/sysbio/syz020.

Boskova, V., Stadler, T. and Magnus, C. (2018) "The influence of phylodynamic model specifications on parameter estimates of the Zika virus epidemic," Virus Evolution, 4(1). doi:10.1093/ve/vex044.

Bouckaert, R. et al. (2019) "BEAST 2.5: An advanced software platform for Bayesian evolutionary analysis," PLOS Computational Biology, 15(4), p. e1006650. Available at: https://doi.org/10.1371/journal.pcbi.1006650.

Byrne, A.W. et al. (2020) "Inferred duration of infectious period of SARS-CoV-2: Rapid scoping review and analysis of available evidence for asymptomatic and symptomatic COVID-19 cases,” BMJ Open, 10(8), pp. 1-16. doi:10.1136/bmjopen-2020-039856. Cori, A. et al. (2013) “A New Framework and Software to Estimate Time-Varying Reproduction Numbers During Epidemics," American Journal of Epidemiology, 178(9), pp. 1505-1512. doi:10.1093/aje/kwt133.

Cowling, B.J. et al. (2020) "Impact assessment of non-pharmaceutical interventions against coronavirus disease 2019 and influenza in Hong Kong: an observational study," The Lancet Public Health, 5(5), pp. e279-e288. doi:10.1016/S2468-2667(20)30090-6.

Dolan, P.T., Whitfield, Z.J. and Andino, R. (2018) "Mapping the Evolutionary Potential of RNA Viruses," Cell Host and Microbe, 23(4), pp. 435-446. doi:10.1016/j.chom.2018.03.012. 
medRxiv preprint doi: https://doi.org/10.1101/2022.02.04.22270165; this version posted February 6, 2022. The copyright holder for this preprint (which was not certified by peer review) is the author/funder, who has granted medRxiv a license to display the preprint in perpetuity.

It is made available under a CC-BY 4.0 International license .

Drummond, A.J. et al. (2003) "Measurably evolving populations," Trends in Ecology \& Evolution, 18(9), pp. 481-488. doi:https://doi.org/10.1016/S0169-5347(03)00216-7.

Drummond, A.J. et al. (2005) "Bayesian Coalescent Inference of Past Population Dynamics from Molecular Sequences," Molecular Biology and Evolution, 22(5), pp. 1185-1192. doi:10.1093/molbev/msi103.

Duchene, S. et al. (2020) "Temporal signal and the phylodynamic threshold of SARS-CoV2,"Virus Evolution, 6(2). doi:10.1093/ve/veaa061.

Dudas, G. et al. (2017) "Virus genomes reveal factors that spread and sustained the Ebola epidemic," Nature [Preprint]. doi:10.1038/nature22040.

European Centre for Disease Prevention and Control (2020) Guidelines for the implementation of non-pharmaceutical interventions against COVID-19 Key messages General considerations on NPI to control COVID-19.

Faria, N.R. et al. (2017) "Establishment and cryptic transmission of Zika virus in Brazil and the Americas," Nature, 546(7658), pp. 406-410. doi:10.1038/nature22401.

Faria, N.R. et al. (2021) "Genomics and epidemiology of the P.1 SARS-CoV-2 lineage in Manaus, Brazil,”Science, 372(6544), pp. 815 LP - 821. doi:10.1126/science.abh2644.

Flaxman, S. et al. (2020) "Estimating the effects of non-pharmaceutical interventions on COVID-19 in Europe,” Nature, 584(7820), pp. 257-261. doi:10.1038/s41586-020-2405-7.

Fraser, C. (2007) "Estimating Individual and Household Reproduction Numbers in an Emerging Epidemic," PLoS ONE. Edited by A. Galvani, 2(8), p. e758.

doi:10.1371/journal.pone.0000758.

Frost, S.D.W. et al. (2015) “Eight challenges in phylodynamic inference,” Epidemics. 2014/09/16, 10, pp. 88-92. doi:10.1016/j.epidem.2014.09.001.

Ghafari, M. et al. (2022) "Purifying selection determines the short-term time dependency of evolutionary rates in SARS-CoV-2 and pH1N1 influenza," Molecular Biology and Evolution, p. msac009. doi:10.1093/molbev/msac009.

Gill, M.S. et al. (2013) "Improving Bayesian population dynamics inference: a coalescentbased model for multiple loci," Molecular biology and evolution. 2012/11/22, 30(3), pp. 713724. doi:10.1093/molbev/mss265.

Gorbalenya, A.E. et al. (2020) "The species Severe acute respiratory syndrome-related coronavirus: classifying 2019-nCoV and naming it SARS-CoV-2," Nature Microbiology, 5(4), pp. 536-544. doi:10.1038/s41564-020-0695-z. 
medRxiv preprint doi: https://doi.org/10.1101/2022.02.04.22270165; this version posted February 6, 2022. The copyright holder for this preprint (which was not certified by peer review) is the author/funder, who has granted medRxiv a license to display the preprint in perpetuity.

It is made available under a CC-BY 4.0 International license .

Gostic, K.M. et al. (2020) "Practical considerations for measuring the effective reproductive number, Rt," PLOS Computational Biology, 16(12), p. e1008409. Available at: https://doi.org/10.1371/journal.pcbi.1008409.

Grubaugh, N.D. et al. (2017) "Genomic epidemiology reveals multiple introductions of Zika virus into the United States," Nature, 546(7658), pp. 401-405. doi:10.1038/nature22400. Hadfield, J. et al. (2018) "Nextstrain: real-time tracking of pathogen evolution," Bioinformatics, 34(23), pp. 4121-4123. doi:10.1093/bioinformatics/bty407.

Hall, M.D., Woolhouse, M.E.J. and Rambaut, A. (2016) "The effects of sampling strategy on the quality of reconstruction of viral population dynamics using Bayesian skyline family coalescent methods: A simulation study," Virus evolution, 2(1), pp. vew003-vew003. doi:10.1093/ve/vew003.

Harvey, W.T. et al. (2021) "SARS-CoV-2 variants, spike mutations and immune escape," Nature Reviews Microbiology, 19(7), pp. 409-424. doi:10.1038/s41579-021-00573-0.

Hasegawa, M., Kishino, H. and Yano, T. (1985) "Dating of the human-ape splitting by a molecular clock of mitochondrial DNA," Journal of Molecular Evolution, 22(2), pp. 160174. doi:10.1007/BF02101694.

Hidano, A. and Gates, M.C. (2019) "Assessing biases in phylodynamic inferences in the presence of super-spreaders," Veterinary Research, 50(1), p. 74. doi:10.1186/s13567-0190692-5.

Hill, V. and Baele, G. (2019) "Bayesian Estimation of Past Population Dynamics in BEAST 1.10 Using the Skygrid Coalescent Model," Molecular Biology and Evolution, 36(11), pp. 2620-2628. doi:10.1093/molbev/msz172.

IBGE (2020) Population Projections. Available at:

https://www.ibge.gov.br/en/statistics/social/population.html (Accessed: July 25, 2021). Jombart, T. et al. (2014) "Bayesian Reconstruction of Disease Outbreaks by Combining Epidemiologic and Genomic Data," PLOS Computational Biology, 10(1), pp. e1003457-. Available at: https://doi.org/10.1371/journal.pcbi.1003457.

Kalyaanamoorthy, S. et al. (2017) "ModelFinder: fast model selection for accurate phylogenetic estimates," Nature Methods, 14(6), pp. 587-589. doi:10.1038/nmeth.4285. Karcher, M.D. et al. (2016) "Quantifying and Mitigating the Effect of Preferential Sampling on Phylodynamic Inference,” PLoS computational biology, 12(3), pp. e1004789-e1004789. doi:10.1371/journal.pcbi.1004789. 
medRxiv preprint doi: https://doi.org/10.1101/2022.02.04.22270165; this version posted February 6, 2022. The copyright holder for this preprint (which was not certified by peer review) is the author/funder, who has granted medRxiv a license to display the preprint in It is made available under a CC-BY 4.0 International license.

Katoh, K. et al. (2002) "MAFFT: a novel method for rapid multiple sequence alignment based on fast Fourier transform," Nucleic Acids Research, 30(14), pp. 3059-3066. doi:10.1093/nar/gkf436.

Kullback, S. and Leibler, R.A. (1951) "On Information and Sufficiency," The Annals of Mathematical Statistics, 22(1), pp. 79-86. doi:10.1214/aoms/1177729694.

Lesley, S. et al. (2021) “Track Omicron’s spread with molecular data,” Science, 374(6574), pp. 1454-1455. doi:10.1126/science.abn4543.

Lin, J. (1991) "Divergence measures based on the Shannon entropy," IEEE Transactions on Information Theory, 37(1), pp. 145-151. doi:10.1109/18.61115.

Liu, Q. et al. (2020) "Population Genetics of SARS-CoV-2: Disentangling Effects of Sampling Bias and Infection Clusters," Genomics, Proteomics \& Bioinformatics, 18(6), pp. 640-647. doi:https://doi.org/10.1016/j.gpb.2020.06.001.

McAloon, C. et al. (2020) "Incubation period of COVID-19: a rapid systematic review and meta-analysis of observational research," BMJ Open, 10(8), p. e039652.

doi:10.1136/bmjopen-2020-039652.

Minh, B.Q. et al. (2020) "IQ-TREE 2: New Models and Efficient Methods for Phylogenetic Inference in the Genomic Era," Molecular Biology and Evolution, 37(5), pp. 1530-1534. doi:10.1093/molbev/msaa015.

Nadeau, S.A. et al. (2021) "The origin and early spread of SARS-CoV-2 in Europe," Proceedings of the National Academy of Sciences, 118(9), p. e2012008118. doi:10.1073/pnas.2012008118.

Nascimento, V.A. do et al. (2020) "Genomic and phylogenetic characterisation of an imported case of SARS-CoV-2 in Amazonas State, Brazil," Memórias do Instituto Oswaldo Cruz, 115. doi:10.1590/0074-02760200310.

Naveca, F.G. et al. (2021) "COVID-19 in Amazonas, Brazil, was driven by the persistence of endemic lineages and P.1 emergence," Nature Medicine, 27(7), pp. 1230-1238. doi:10.1038/s41591-021-01378-7.

Parag, K. v. (2021) "Improved estimation of time-varying reproduction numbers at low case incidence and between epidemic waves," PLOS Computational Biology. Edited by S.L. Kosakovsky Pond, 17(9), p. e1009347. doi:10.1371/journal.pcbi.1009347.

Parag, K. v, du Plessis, L. and Pybus, O.G. (2020) "Jointly Inferring the Dynamics of Population Size and Sampling Intensity from Molecular Sequences," Molecular Biology and Evolution, 37(8), pp. 2414-2429. doi:10.1093/molbev/msaa016. 
medRxiv preprint doi: https://doi.org/10.1101/2022.02.04.22270165; this version posted February 6, 2022. The copyright holder for this preprint (which was not certified by peer review) is the author/funder, who has granted medRxiv a license to display the preprint in It is made available under a CC-BY 4.0 International license.

Prete, C.A. et al. (2021) "Serial interval distribution of SARS-CoV-2 infection in Brazil," Journal of travel medicine, 28(2), pp. 1-3. doi:10.1093/jtm/taaa115.

Pullano, G. et al. (2021) "Underdetection of cases of COVID-19 in France threatens epidemic control," Nature, 590(7844), pp. 134-139. doi:10.1038/s41586-020-03095-6.

Rai, B., Shukla, A. and Dwivedi, L.K. (2021) "Estimates of serial interval for COVID-19: A systematic review and meta-analysis," Clinical epidemiology and global health. 2020/08/26, 9, pp. 157-161. doi:10.1016/j.cegh.2020.08.007.

Rambaut, A. et al. (2016) "Exploring the temporal structure of heterochronous sequences using TempEst (formerly Path-O-Gen),"Virus evolution, 2(1), pp. vew007-vew007. doi:10.1093/ve/vew007.

Rambaut, A. et al. (2018) "Posterior Summarization in Bayesian Phylogenetics Using Tracer 1.7,” Systematic biology, 67(5), pp. 901-904. doi:10.1093/sysbio/syy032.

Rambaut, A. et al. (2020) "A dynamic nomenclature proposal for SARS-CoV-2 lineages to assist genomic epidemiology," Nature Microbiology, 5(11), pp. 1403-1407. doi:10.1038/s41564-020-0770-5.

Romano, C.M. and Melo, F.L. (2021) “Genomic surveillance of SARS-CoV-2: A race against time," The Lancet Regional Health - Americas, 0(0), p. 100029. doi:10.1016/j.lana.2021.100029.

Sabino, E.C. et al. (2021) "Resurgence of COVID-19 in Manaus, Brazil, despite high seroprevalence.," Lancet (London, England), 397(10273), pp. 452-455. doi:10.1016/S01406736(21)00183-5.

Shu, Y. and McCauley, J. (2017) "GISAID: Global initiative on sharing all influenza data from vision to reality," Euro surveillance : bulletin Europeen sur les maladies transmissibles = European communicable disease bulletin, 22(13), p. 30494. doi:10.2807/15607917.ES.2017.22.13.30494.

de Silva, E., Ferguson, N.M. and Fraser, C. (2012) "Inferring pandemic growth rates from sequence data," Journal of The Royal Society Interface, 9(73), pp. 1797-1808. doi:10.1098/rsif.2011.0850.

de Souza, W.M. et al. (2020) "Epidemiological and clinical characteristics of the COVID-19 epidemic in Brazil," Nature Human Behaviour, 4(8), pp. 856-865. doi:10.1038/s41562-0200928-4.

Stack, J.C. et al. (2010) "Protocols for sampling viral sequences to study epidemic dynamics," Journal of the Royal Society, Interface. 2010/02/10, 7(48), pp. 1119-1127. doi:10.1098/rsif.2009.0530. 
medRxiv preprint doi: https://doi.org/10.1101/2022.02.04.22270165; this version posted February 6, 2022. The copyright holder for this preprint (which was not certified by peer review) is the author/funder, who has granted medRxiv a license to display the preprint in perpetuity.

It is made available under a CC-BY 4.0 International license .

Stadler, T. et al. (2013) "Birth-death skyline plot reveals temporal changes of epidemic spread in HIV and hepatitis C virus (HCV)," Proceedings of the National Academy of Sciences, 110(1), pp. 228 LP - 233. doi:10.1073/pnas.1207965110.

Suchard, M.A. et al. (2018) "Bayesian phylogenetic and phylodynamic data integration using BEAST 1.10,”Virus evolution, 4(1), pp. vey016-vey016. doi:10.1093/ve/vey016.

Tamura, K. and Nei, M. (1993) "Estimation of the number of nucleotide substitutions in the control region of mitochondrial DNA in humans and chimpanzees.," Molecular Biology and Evolution, 10(3), pp. 512-526. doi:10.1093/oxfordjournals.molbev.a040023.

The World Bank (2021) Population, total - Hong Kong SAR, China. Available at: https://data.worldbank.org/indicator/SP.POP.TOTL?locations=HK (Accessed: July 25, 2021).

Tsang, T.K. et al. (2020) "Effect of changing case definitions for COVID-19 on the epidemic curve and transmission parameters in mainland China: a modelling study.," The Lancet.

Public health, 5(5), pp. e289-e296. doi:10.1016/S2468-2667(20)30089-X.

UK Health Security Agency (2022) The R value and growth rate, https://www.gov.uk/guidance/the-r-value-and-growth-rate.

Vasylyeva, T.I. et al. (2020) "Phylodynamics helps to evaluate the impact of an HIV prevention intervention," Viruses, 12(4), pp. 1-15. doi:10.3390/v12040469.

Verity, R. et al. (2020) "Estimates of the severity of coronavirus disease 2019: a model-based analysis.," The Lancet. Infectious diseases, 20(6), pp. 669-677. doi:10.1016/S14733099(20)30243-7.

Volz, E. et al. (2021) "Evaluating the Effects of SARS-CoV-2 Spike Mutation D614G on Transmissibility and Pathogenicity," Cell, 184(1), pp. 64-75.e11.

doi:https://doi.org/10.1016/j.cell.2020.11.020.

Volz, E.M. and Didelot, X. (2018) "Modeling the Growth and Decline of Pathogen Effective Population Size Provides Insight into Epidemic Dynamics and Drivers of Antimicrobial Resistance,” Systematic Biology, 67(4), pp. 719-728. doi:10.1093/sysbio/syy007.

Volz, E.M., Koelle, K. and Bedford, T. (2013) "Viral phylodynamics," PLoS computational biology. 2013/03/21, 9(3), pp. e1002947-e1002947. doi:10.1371/journal.pcbi.1002947.

Wallinga, J. and Teunis, P. (2004) “Different Epidemic Curves for Severe Acute Respiratory Syndrome Reveal Similar Impacts of Control Measures," American Journal of Epidemiology, 160(6), pp. 509-516. doi:10.1093/aje/kwh255. 
medRxiv preprint doi: https://doi.org/10.1101/2022.02.04.22270165; this version posted February 6, 2022. The copyright holder for this preprint (which was not certified by peer review) is the author/funder, who has granted medRxiv a license to display the preprint in It is made available under a CC-BY 4.0 International license.

Wallinga and Lipsitch (2007) "How generation intervals shape the relationship between growth rates and reproductive numbers," Proceedings of the Royal Society B: Biological Sciences, 274(1609), pp. 599-604. doi:10.1098/rspb.2006.3754.

World Health Organisation (2020) Public Health Emergency of International Concern (PHEIC).

World Health Organisation (2021a) Genomic sequencing of SARS-CoV-2 A guide to implementation for maximum impact on public health.

World Health Organisation (2021b) Guidance for surveillance of SARS-CoV-2 variants Interim guidance.

World Health Organisation (2022) Coronavirus disease (COVID-19) Weekly Epidemiological Update and Weekly Operational Update, https://www.who.int/emergencies/diseases/novelcoronavirus-2019/situation-reports.

Zhao, S. et al. (2020) "Preliminary estimation of the basic reproduction number of novel coronavirus (2019-nCoV) in China, from 2019 to 2020: A data-driven analysis in the early phase of the outbreak," International journal of infectious diseases : IJID : official publication of the International Society for Infectious Diseases. 2020/01/30, 92, pp. 214-217. doi:10.1016/j.ijid.2020.01.050.

Zhu, N. et al. (2020) "A Novel Coronavirus from Patients with Pneumonia in China, 2019," New England Journal of Medicine, 382(8), pp. 727-733. doi:10.1056/NEJMoa2001017. 
medRxiv preprint doi: https://doi.org/10.1101/2022.02.04.22270165; this version posted February 6, 2022. The copyright holder for this preprint (which was not certified by peer review) is the author/funder, who has granted medRxiv a license to display the preprint in It is made available under a CC-BY 4.0 International license .

\section{Supplementary Figures and Tables}

Supplementary Table 1: Key parameters and definitions for SARS-CoV-2

\begin{tabular}{|c|c|}
\hline Parameter & Definition \\
\hline $\begin{array}{l}\text { Basic reproduction number } \\
\qquad\left(R_{0}\right)\end{array}$ & $\begin{array}{c}\text { Average number of individuals infected by a single infected } \\
\text { person in a fully susceptible population }\end{array}$ \\
\hline $\begin{array}{l}\text { Time-varying or effective } \\
\text { reproduction number }\left(R_{t}\right)\end{array}$ & $\begin{array}{l}\text { Average number of secondary infections generated per } \\
\text { effective primary case at a certain time point and in the } \\
\text { presence of susceptible depletion or interventions }\end{array}$ \\
\hline Growth rate $\left(r_{t}\right)$ & $\begin{array}{l}\text { Rate of change of the logarithm of the number of new cases } \\
\text { per unit of time }\end{array}$ \\
\hline Incubation period & Time between infection and symptom onset \\
\hline Infectious period & $\begin{array}{l}\text { Period in which an infectious host can transmit infectious } \\
\text { agents to a susceptible individual }\end{array}$ \\
\hline Generation interval & Time between infection events in an infector-infectee pair \\
\hline Date of origin & Date in which viral variant is thought to have emerged \\
\hline Serial Interval & Time between symptom onsets in an infector-infectee pair \\
\hline
\end{tabular}




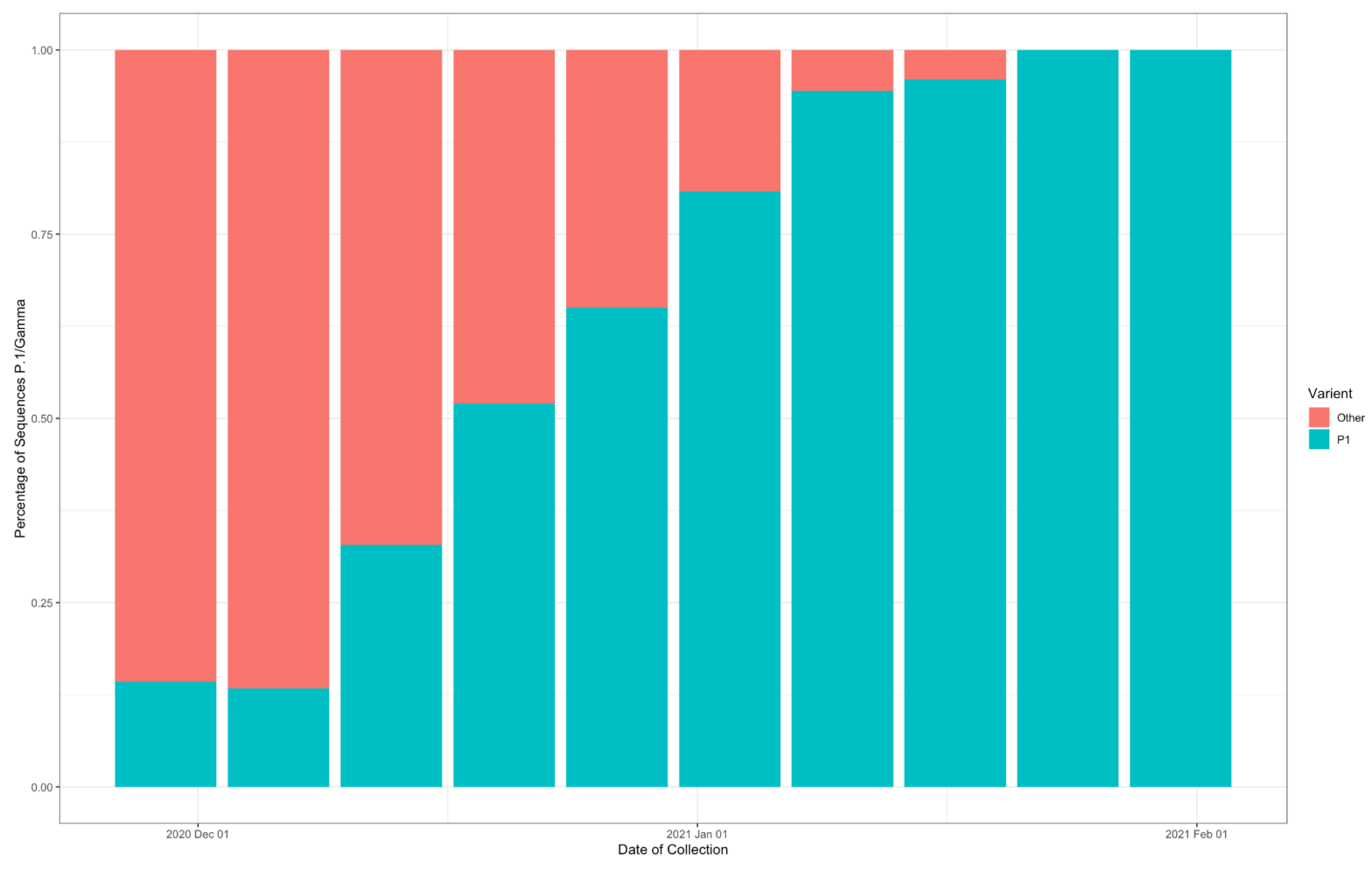

Supplementary Figure 1: The proportion of P.1 sequences compared to non-P.1

sequences found on GISaid (Shu and McCauley, 2017).
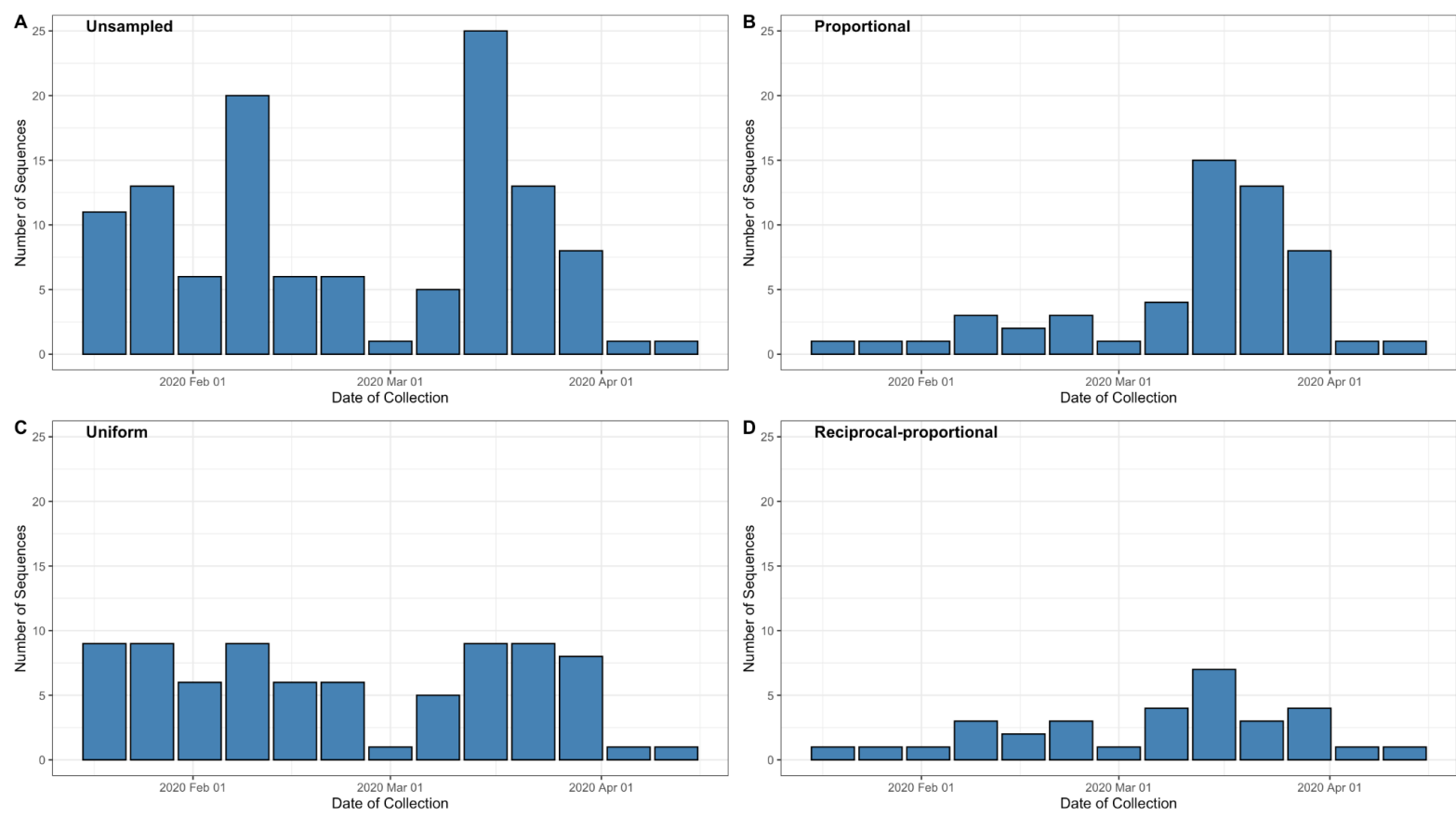

Supplementary Figure 2: Number of sequences for each week and sampling scheme for Hong Kong dataset. 

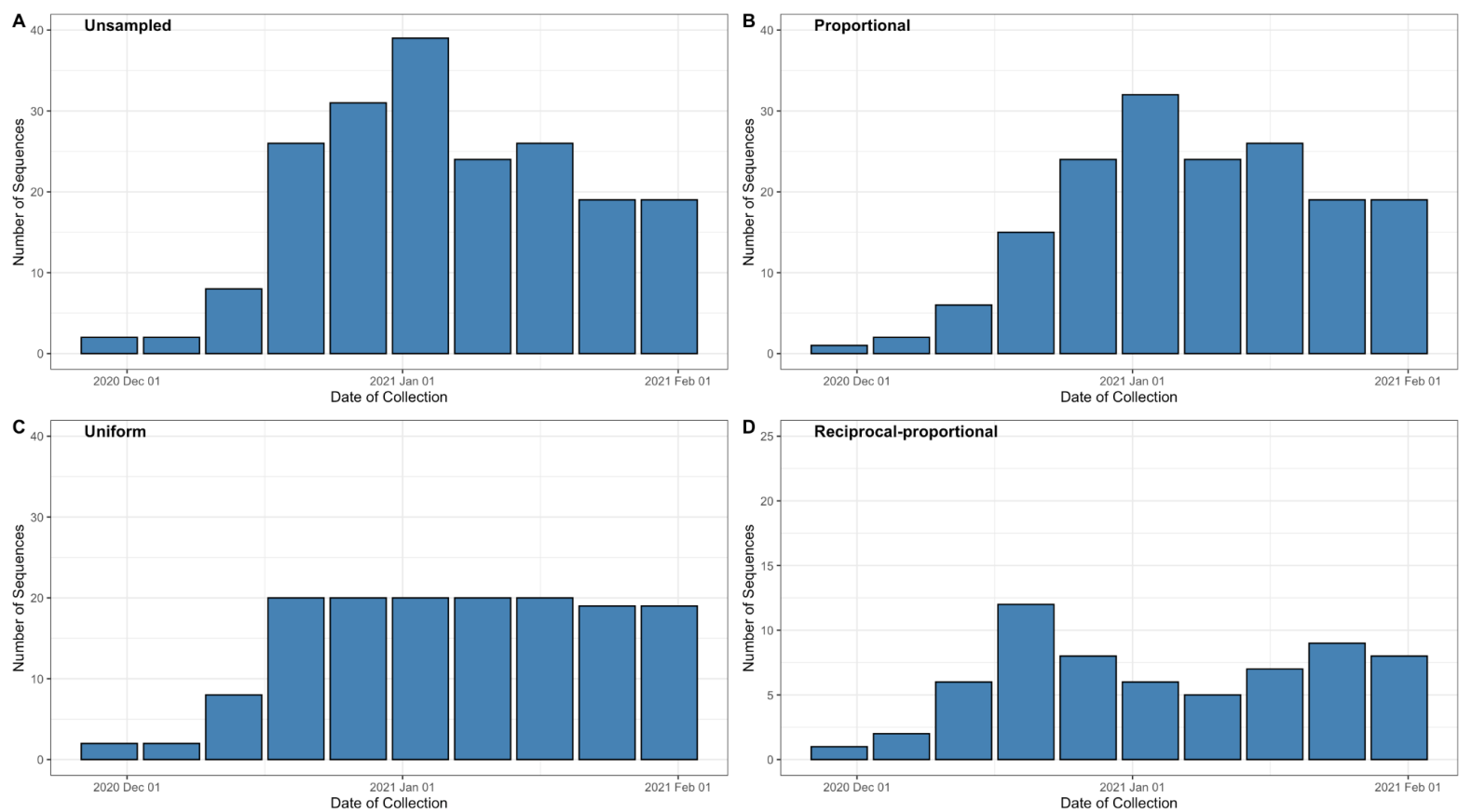

Supplementary Figure 3: Number of sequences for each week and sampling scheme for Amazonas dataset.

Supplementary Table 2: TMRCA and mean substitution rate both with 95\% BCI for each sampling strategy for Hong Kong and Amazonas datasets alongside the Jensen-Shannon distance. Full posterior distribution of the TMRCA and substitution rates obtained under the different sampling strategies can be found in Figure 3B and D and Supplementary Figure 4.

\begin{tabular}{|c|c|c|c|}
\hline $\begin{array}{l}\text { Sampling } \\
\text { Strategy }\end{array}$ & Dataset & TMRCA (95\% BCI) & $\begin{array}{c}\text { Mean } \\
\text { Substitution } \\
\text { Rate (95\% BCI, } \\
\text { subs/site/year, } \\
\text { s/s/y) }\end{array}$ \\
\hline \multirow{2}{*}{ Unsampled } & Hong Kong & $\begin{array}{l}2^{\text {nd }} \text { December } 2019\left(10^{\text {th }}\right. \\
\text { November } 2019-24^{\text {th }} \\
\text { December } 2019)\end{array}$ & $\begin{array}{c}1.12 \times 10^{-3} \\
\left(9.16 \times 10^{-4}-\right. \\
\left.1.35 \times 10^{-3}\right)\end{array}$ \\
\hline & Brazil & $\begin{array}{c}30^{\text {th }} \text { October } 2020\left(8^{\text {th }} \text { October }\right. \\
\left.2020-13^{\text {th }} \text { December } 2020\right)\end{array}$ & $\begin{array}{c}4.58 \times 10^{-4} \\
\left(3.69 \times 10^{-4}-\right. \\
\left.5.56 \times 10^{-4}\right)\end{array}$ \\
\hline
\end{tabular}


medRxiv preprint doi: https://doi.org/10.1101/2022.02.04.22270165; this version posted February 6, 2022. The copyright holder for this preprint (which was not certified by peer review) is the author/funder, who has granted medRxiv a license to display the preprint in It is made available under a CC-BY 4.0 International license .

\begin{tabular}{|c|c|c|c|}
\hline \multirow{2}{*}{ Proportional } & Hong Kong & $\begin{array}{c}24^{\text {th }} \text { December } 2019\left(21^{\text {st }}\right. \\
\text { November } 2019-11^{\text {th }} \text { January } \\
2020)\end{array}$ & $\begin{array}{c}1.39 \times 10^{-3} \\
\left(9.28 \times 10^{-4}-\right. \\
\left.2.48 \times 10^{-3}\right)\end{array}$ \\
\hline & Brazil & $\begin{array}{l}30^{\text {th }} \text { October } 2020\left(25^{\text {th }} \text { August }\right. \\
\left.2020-29^{\text {th }} \text { November } 2020\right)\end{array}$ & $\begin{array}{c}4.60 \times 10^{-4} \\
\left(3.70 \times 10^{-4}-\right. \\
\left.5.56 \times 10^{-4}\right)\end{array}$ \\
\hline \multirow{2}{*}{ Uniform } & Hong Kong & $\begin{array}{c}13^{\text {th }} \text { December } 2019\left(18^{\text {th }}\right. \\
\text { November } 2019-4^{\text {th }} \text { January } \\
2020)\end{array}$ & $\begin{array}{c}1.64 \times 10^{-3} \\
\left(1.22 \times 10^{-3}-\right. \\
\left.2.09 \times 10^{-3}\right)\end{array}$ \\
\hline & Brazil & $\begin{array}{l}27^{\text {th }} \text { October } 2020\left(5^{\text {th }} \text { October }\right. \\
\left.2020-25^{\text {th }} \text { November } 2020\right)\end{array}$ & $\begin{array}{c}4.60 \times 10^{-4} \\
\left(3.70 \times 10^{-4}-\right. \\
\left.5.56 \times 10^{-4}\right)\end{array}$ \\
\hline \multirow{2}{*}{$\begin{array}{l}\text { Reciprocal- } \\
\text { proportional }\end{array}$} & Hong Kong & $\begin{array}{c}6^{\text {th }} \text { December } 2019\left(10^{\text {th }}\right. \\
\text { November } 2019-28^{\text {th }} \text { December } \\
2019)\end{array}$ & $\begin{array}{c}1.30 \times 10^{-3} \\
\left(1.03 \times 10^{-3}-\right. \\
\left.1.59 \times 10^{-3}\right)\end{array}$ \\
\hline & Brazil & $\begin{array}{c}30^{\text {th }} \text { October } 2020\left(27^{\text {th }}\right. \\
\text { September } 2020-25^{\text {th }} \text { November } \\
2020)\end{array}$ & $\begin{array}{c}4.00 \times 10^{-4} \\
\left(2.56 \times 10^{-4}-\right. \\
\left.5.55 \times 10^{-4}\right)\end{array}$ \\
\hline
\end{tabular}


medRxiv preprint doi: https://doi.org/10.1101/2022.02.04.22270165; this version posted February 6, 2022. The copyright holder for this preprint (which was not certified by peer review) is the author/funder, who has granted medRxiv a license to display the preprint in It is made available under a CC-BY 4.0 International license.
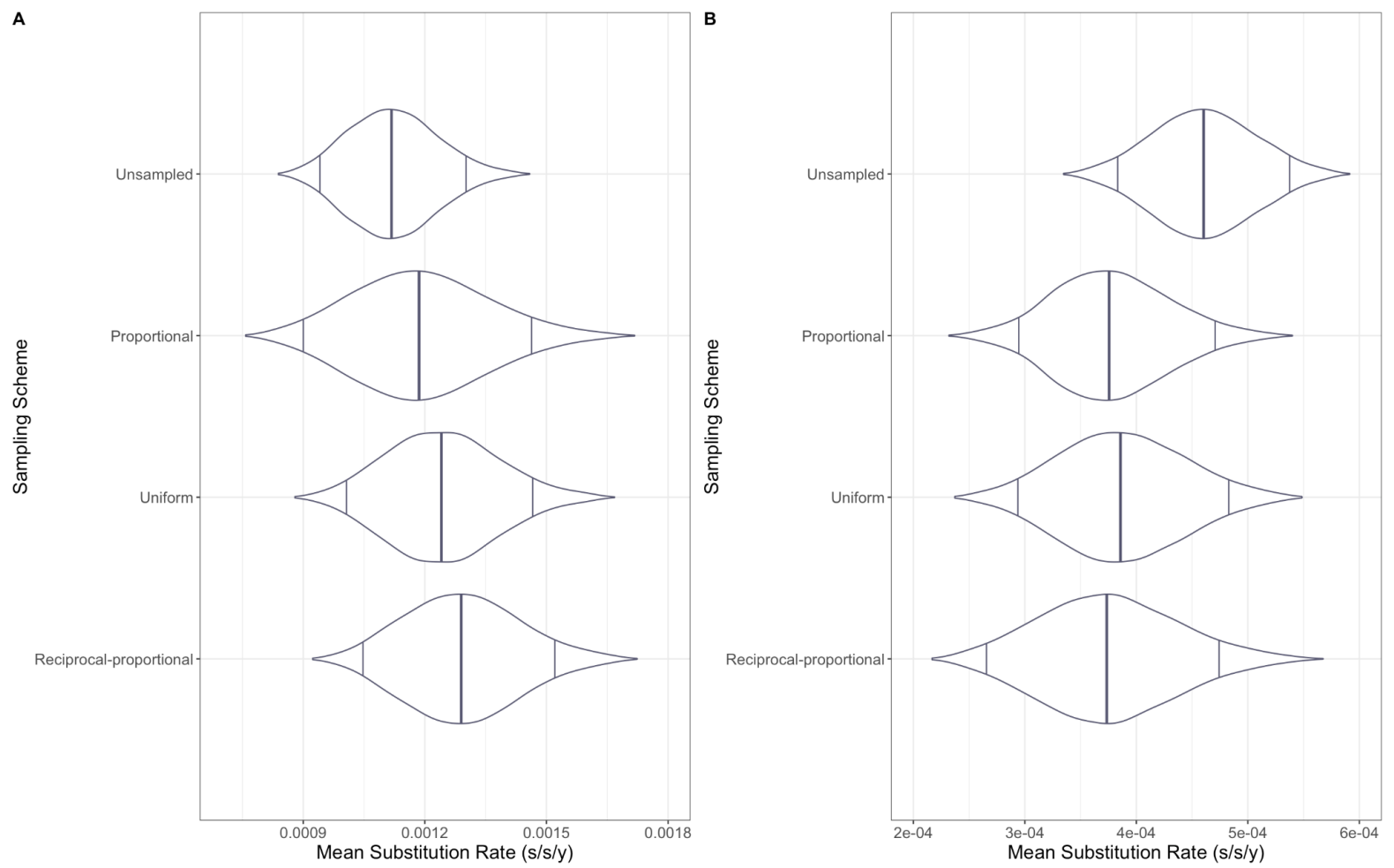

Supplementary Figure 4: Mean substitution rate (s/s/y) for Hong Kong and Brazil. Figure 1A represents Hong Kong with Figure 1B representing the Amazonas.

Supplementary Table 3: Accession ID of each Hong Kong sequence for each sampling strategy used within this study

\begin{tabular}{|l|l|l|l|}
\hline Unsampled & Proportional & Uniform & $\begin{array}{c}\text { Reciprocal- } \\
\text { proportional }\end{array}$ \\
\hline EPI_ISL_412028 & EPI_ISL_414517 & EPI_ISL_412029 & EPI_ISL_412028 \\
\hline EPI_ISL_412029 & EPI_ISL_414519 & EPI_ISL_414517 & EPI_ISL_412029 \\
\hline EPI_ISL_412030 & EPI_ISL_414527 & EPI_ISL_414519 & EPI_ISL_412030 \\
\hline EPI_ISL_414517 & EPI_ISL_418815 & EPI_ISL_414527 & EPI_ISL_414517 \\
\hline EPI_ISL_414519 & EPI_ISL_419224 & EPI_ISL_414569 & EPI_ISL_414519 \\
\hline EPI_ISL_414527 & EPI_ISL_419229 & EPI_ISL_414571 & EPI_ISL_414527 \\
\hline EPI_ISL_414528 & EPI_ISL_419232 & EPI_ISL_416314 & EPI_ISL_414528 \\
\hline EPI_ISL_414569 & EPI_ISL_450404 & EPI_ISL_417064 & EPI_ISL_414569 \\
\hline EPI_ISL_414571 & EPI_ISL_450405 & EPI_ISL_417443 & EPI_ISL_414571 \\
\hline EPI_ISL_416314 & EPI_ISL_450410 & EPI_ISL_419214 & EPI_ISL_416314 \\
\hline
\end{tabular}




\begin{tabular}{|c|c|c|c|}
\hline EPI_ISL_417064 & EPI_ISL_476801 & EPI_ISL_419215 & EPI_ISL_417064 \\
\hline EPI_ISL_417176 & EPI_ISL_476802 & EPI_ISL_419217 & EPI_ISL_417176 \\
\hline EPI_ISL_417178 & EPI_ISL_476803 & EPI_ISL_419224 & EPI_ISL_417178 \\
\hline EPI_ISL_417181 & EPI_ISL_497769 & EPI_ISL_419225 & EPI_ISL_417181 \\
\hline EPI_ISL_417185 & EPI_ISL_497773 & EPI_ISL_419227 & EPI_ISL_417185 \\
\hline EPI_ISL_417187 & EPI_ISL_497775 & EPI_ISL_419228 & EPI_ISL_417187 \\
\hline EPI_ISL_417188 & EPI_ISL_497784 & EPI_ISL_419229 & EPI_ISL_417188 \\
\hline EPI_ISL_417193 & EPI_ISL_497786 & EPI_ISL_419231 & EPI_ISL_417193 \\
\hline EPI_ISL_417197 & EPI_ISL_497791 & EPI_ISL_419232 & EPI_ISL_417197 \\
\hline EPI_ISL_417443 & EPI_ISL_497796 & EPI_ISL_419245 & EPI_ISL_417443 \\
\hline EPI_ISL_418815 & EPI_ISL_497799 & EPI_ISL_419247 & EPI_ISL_418815 \\
\hline EPI_ISL_419214 & EPI_ISL_497806 & EPI_ISL_419250 & EPI_ISL_419214 \\
\hline EPI_ISL_419215 & EPI_ISL_497808 & EPI_ISL_419252 & EPI_ISL_419215 \\
\hline EPI_ISL_419216 & EPI_ISL_497810 & EPI_ISL_434564 & EPI_ISL_419216 \\
\hline EPI_ISL_419217 & EPI_ISL_497811 & EPI_ISL_434565 & EPI_ISL_419217 \\
\hline EPI_ISL_419219 & EPI_ISL_497818 & EPI_ISL_434567 & EPI_ISL_419219 \\
\hline EPI_ISL_419221 & EPI_ISL_497819 & EPI_ISL_434568 & EPI_ISL_419221 \\
\hline EPI_ISL_419222 & EPI_ISL_497821 & EPI_ISL_434569 & EPI_ISL_419222 \\
\hline EPI_ISL_419224 & EPI_ISL_497823 & EPI_ISL_434570 & EPI_ISL_419224 \\
\hline EPI_ISL_419225 & EPI_ISL_497824 & EPI_ISL_434571 & EPI_ISL_419225 \\
\hline EPI_ISL_419226 & EPI_ISL_497840 & EPI_ISL_450405 & EPI_ISL_419226 \\
\hline EPI_ISL_419227 & EPI_ISL_497845 & EPI_ISL_450408 & EPI_ISL_419227 \\
\hline EPI_ISL_419228 & EPI_ISL_497846 & EPI_ISL_450409 & EPI_ISL_419228 \\
\hline EPI_ISL_419229 & EPI_ISL_497847 & EPI_ISL_450410 & EPI_ISL_419229 \\
\hline EPI_ISL_419231 & EPI_ISL_497850 & EPI_ISL_450411 & EPI_ISL_419231 \\
\hline EPI_ISL_419232 & EPI_ISL_497856 & EPI_ISL_476801 & EPI_ISL_419232 \\
\hline EPI_ISL_419245 & EPI_ISL_497865 & EPI_ISL_476802 & EPI_ISL_419245 \\
\hline EPI_ISL_419247 & EPI_ISL_497870 & EPI_ISL_476804 & EPI_ISL_419247 \\
\hline EPI_ISL_419250 & EPI_ISL_516798 & EPI_ISL_497769 & EPI_ISL_419250 \\
\hline EPI_ISL_419252 & EPI_ISL_539820 & EPI_ISL_497771 & EPI_ISL_419252 \\
\hline EPI_ISL_434560 & EPI_ISL_539850 & EPI_ISL_497783 & EPI_ISL_434563 \\
\hline EPI_ISL_434563 & EPI_ISL_539851 & EPI_ISL_497784 & EPI_ISL_434564 \\
\hline
\end{tabular}


medRxiv preprint doi: https://doi.org/10.1101/2022.02.04.22270165; this version posted February 6, 2022. The copyright holder for this preprint (which was not certified by peer review) is the author/funder, who has granted medRxiv a license to display the preprint in It is made available under a CC-BY 4.0 International license .

\begin{tabular}{|c|c|c|c|}
\hline EPI_ISL_434564 & EPI_ISL_610167 & EPI_ISL_ 497791 & EPI_ISL_434565 \\
\hline EPI_ISL_434565 & EPI_ISL_610168 & EPI_ISL_497806 & EPI_ISL_434566 \\
\hline EPI_ISL_434566 & EPI_ISL_610169 & EPI_ISL_497810 & EPI_ISL_434567 \\
\hline EPI_ISL_434567 & EPI_ISL_610170 & EPI_ISL_497811 & EPI_ISL_434568 \\
\hline EPI_ISL_434568 & EPI_ISL_610171 & EPI_ISL_497813 & EPI_ISL_434569 \\
\hline EPI_ISL_434569 & EPI_ISL_610172 & EPI_ISL_497818 & EPI_ISL_434570 \\
\hline EPI_ISL_434570 & EPI_ISL_610173 & EPI_ISL_497821 & EPI_ISL_434571 \\
\hline EPI_ISL_434571 & EPI_ISL_610174 & EPI_ISL_497823 & EPI_ISL_450405 \\
\hline EPI_ISL_450404 & EPI_ISL_610175 & EPI_ISL_497824 & EPI_ISL_450408 \\
\hline EPI_ISL_450405 & EPI_ISL_610177 & EPI_ISL_497826 & EPI_ISL_450409 \\
\hline EPI_ISL_450408 & & EPI_ISL_497827 & EPI_ISL_450410 \\
\hline EPI_ISL_450409 & & EPI_ISL_497831 & EPI_ISL_450411 \\
\hline EPI_ISL_450410 & & EPI_ISL_497832 & EPI_ISL_450412 \\
\hline EPI_ISL_450411 & & EPI_ISL_497846 & EPI_ISL_476802 \\
\hline EPI_ISL_450412 & & EPI_ISL_ 497847 & EPI_ISL_476804 \\
\hline EPI_ISL_476801 & & EPI_ISL_497848 & EPI_ISL_497769 \\
\hline EPI_ISL_476802 & & EPI_ISL_497856 & EPI_ISL_497771 \\
\hline EPI_ISL_476803 & & EPI_ISL_497860 & EPI_ISL_497773 \\
\hline EPI_ISL_476804 & & EPI_ISL_497865 & EPI_ISL_497783 \\
\hline EPI_ISL_497769 & & EPI_ISL_539820 & EPI_ISL_497784 \\
\hline EPI_ISL_497771 & & EPI_ISL_539850 & EPI_ISL_497791 \\
\hline EPI_ISL_497773 & & EPI_ISL_ 539851 & EPI_ISL_497797 \\
\hline EPI_ISL_497775 & & EPI_ISL_610165 & EPI_ISL_497811 \\
\hline EPI_ISL_497783 & & EPI_ISL_ 610166 & EPI_ISL_497812 \\
\hline EPI_ISL_497784 & & EPI_ISL_610167 & EPI_ISL_497818 \\
\hline EPI_ISL_497786 & & EPI_ISL_610168 & EPI_ISL_497819 \\
\hline EPI_ISL_497791 & & EPI_ISL_610169 & EPI_ISL_497823 \\
\hline EPI_ISL_497796 & & EPI_ISL_ 610171 & EPI_ISL_497824 \\
\hline
\end{tabular}


medRxiv preprint doi: https://doi.org/10.1101/2022.02.04.22270165; this version posted February 6, 2022. The copyright holder for this preprint (which was not certified by peer review) is the author/funder, who has granted medRxiv a license to display the preprint in It is made available under a CC-BY 4.0 International license.

\begin{tabular}{|c|c|c|}
\hline EPI_ISL_497797 & EPI_ISL_610173 & EPI_ISL_497827 \\
\hline EPI_ISL_497798 & EPI_ISL_610174 & EPI_ISL_497831 \\
\hline EPI_ISL_497799 & EPI_ISL_610175 & EPI_ISL_497833 \\
\hline EPI_ISL_497806 & EPI_ISL_ 610177 & EPI_ISL_497848 \\
\hline EPI_ISL_497808 & & EPI_ISL_497850 \\
\hline EPI_ISL_497810 & & EPI_ISL_497856 \\
\hline EPI_ISL_497811 & & EPI_ISL_497860 \\
\hline EPI_ISL_497812 & & EPI_ISL_497864 \\
\hline EPI_ISL_497813 & & EPI_ISL_497865 \\
\hline EPI_ISL_497818 & & EPI_ISL_539850 \\
\hline EPI_ISL_497819 & & EPI ISL 539851 \\
\hline EPI_ISL_497820 & & EPI ISL 610165 \\
\hline EPI_ISL_497821 & & EPI_ISL_610166 \\
\hline EPI_ISL_497823 & & EPI_ISL_ 610172 \\
\hline EPI_ISL_497824 & & EPI_ISL_ 610177 \\
\hline EPI_ISL_497826 & & \\
\hline EPI_ISL_497827 & & \\
\hline EPI_ISL_497831 & & \\
\hline EPI_ISL_497832 & & \\
\hline EPI_ISL_497833 & & \\
\hline EPI_ISL_497840 & & \\
\hline EPI_ISL_497845 & & \\
\hline EPI_ISL_497846 & & \\
\hline EPI_ISL_497847 & & \\
\hline EPI_ISL_497848 & & \\
\hline EPI_ISL_497850 & & \\
\hline EPI ISL 497856 & & \\
\hline
\end{tabular}


medRxiv preprint doi: https://doi.org/10.1101/2022.02.04.22270165; this version posted February 6, 2022. The copyright holder for this preprint (which was not certified by peer review) is the author/funder, who has granted medRxiv a license to display the preprint in It is made available under a CC-BY 4.0 International license .

\begin{tabular}{|l|l|l|l|}
\hline EPI_ISL_497860 & & & \\
\hline EPI_ISL_497864 & & & \\
\hline EPI_ISL_497865 & & & \\
\hline EPI_ISL_497870 & & & \\
\hline EPI_ISL_516798 & & & \\
\hline EPI_ISL_539820 & & & \\
\hline EPI_ISL_539850 & & & \\
\hline EPI_ISL_539851 & & & \\
\hline EPI_ISL_610165 & & & \\
\hline EPI_ISL_610166 & & & \\
\hline EPI_ISL_610167 & & & \\
\hline EPI_ISL_610168 & & & \\
\hline EPI_ISL_610169 & & & \\
\hline EPI_ISL_610170 & & & \\
\hline EPI_ISL_610171 & & & \\
\hline EPI_ISL_610172 & & & \\
\hline EPI_ISL_610173 & & & \\
\hline EPI_ISL_610174 & & & \\
\hline EPI_ISL_610175 & & & \\
\hline EPI_ISL_610177 & & & \\
\hline
\end{tabular}


medRxiv preprint doi: https://doi.org/10.1101/2022.02.04.22270165; this version posted February 6, 2022. The copyright holder for this preprint (which was not certified by peer review) is the author/funder, who has granted medRxiv a license to display the preprint in

It is made available under a CC-BY 4.0 International license.

Supplementary Table 4: Accession ID of each Amazonas State, Brazil sequence for each sampling strategy used within this study

\begin{tabular}{|c|c|c|c|}
\hline Unsampled & Proportional & Uniform & $\begin{array}{l}\text { Reciprocal- } \\
\text { proportional }\end{array}$ \\
\hline EPI_ISL_1034306 & EPI_ISL_1034304 & EPI_ISL_ 1034304 & EPI_ISL_1034306 \\
\hline EPI_ISL_ 1060876 & EPI_ISL_1034306 & EPI_ISL_1034306 & EPI_ISL_1060913 \\
\hline EPI_ISL_ 1060877 & EPI_ISL_1060877 & EPI_ISL_ 1060877 & EPI_ISL_1060914 \\
\hline EPI_ISL_1060881 & EPI_ISL_1060881 & EPI_ISL_1060881 & EPI_ISL_1068149 \\
\hline EPI_ISL_1060888 & EPI_ISL_1060897 & EPI_ISL_ 1060888 & EPI_ISL_ 1068150 \\
\hline EPI_ISL_1060889 & EPI_ISL_1060900 & EPI_ISL_ 1060889 & EPI_ISL_ 1068156 \\
\hline EPI_ISL_ 1060894 & EPI_ISL_1060902 & EPI_ISL_ 1060897 & EPI_ISL_ 1068198 \\
\hline EPI_ISL_ 1060897 & EPI_ISL_1060904 & EPI_ISL_ 1060900 & EPI_ISL_1068258 \\
\hline EPI_ISL_1060900 & EPI_ISL_1060906 & EPI_ISL_ 1060912 & EPI_ISL_1068260 \\
\hline EPI_ISL_ 1060902 & EPI_ISL_1060912 & EPI_ISL_ 1060913 & EPI_ISL_1068262 \\
\hline EPI_ISL_1060904 & EPI_ISL_1060913 & EPI_ISL_1060956 & EPI_ISL_1068263 \\
\hline EPI_ISL_1060906 & EPI_ISL_1060914 & EPI_ISL_1061026 & EPI_ISL_1068264 \\
\hline EPI_ISL_ 1060911 & EPI_ISL_1060918 & EPI_ISL_ 1068111 & EPI_ISL_1068278 \\
\hline EPI_ISL_1060912 & EPI_ISL_1060956 & EPI_ISL_1068149 & EPI_ISL_1068286 \\
\hline EPI_ISL_ 1060913 & EPI_ISL_1061026 & EPI_ISL_ 1068150 & EPI_ISL_ 1068288 \\
\hline EPI_ISL_1060914 & EPI_ISL_1068110 & EPI_ISL_1068154 & EPI_ISL_1166615 \\
\hline EPI_ISL_1060918 & EPI_ISL_1068111 & EPI_ISL_1068158 & EPI_ISL_1213190 \\
\hline EPI_ISL_1060956 & EPI_ISL_1068112 & EPI_ISL_ 1068160 & EPI_ISL_ 1261690 \\
\hline EPI_ISL_ 1061026 & EPI_ISL_1068114 & EPI_ISL_ 1068169 & EPI_ISL_1261694 \\
\hline EPI_ISL_ 1068110 & EPI_ISL_1068149 & EPI_ISL_ 1068198 & EPI_ISL_2777236 \\
\hline EPI_ISL_ 1068111 & EPI_ISL_1068150 & EPI_ISL_ 1068222 & EPI_ISL_ 2777320 \\
\hline EPI_ISL_1068112 & EPI_ISL_1068151 & EPI_ISL_1068225 & EPI_ISL_2777363 \\
\hline EPI_ISL_ 1068114 & EPI_ISL_1068154 & EPI_ISL_1068226 & EPI_ISL_2777375 \\
\hline EPI_ISL_1068149 & EPI_ISL_1068156 & EPI_ISL_1068243 & EPI_ISL_2777376 \\
\hline EPI_ISL_ 1068150 & EPI_ISL_1068158 & EPI_ISL_ 1068248 & EPI_ISL_2777384 \\
\hline EPI_ISL_1068151 & EPI_ISL_1068160 & EPI_ISL_1068249 & EPI_ISL_2777388 \\
\hline EPI_ISL_1068154 & EPI_ISL_1068169 & EPI_ISL_ 1068260 & EPI_ISL_2777397 \\
\hline
\end{tabular}




\begin{tabular}{|c|c|c|c|}
\hline EPI_ISL_ 1068156 & EPI_ISL_1068198 & EPI_ISL_ 1068261 & EPI_ISL_ 2777399 \\
\hline EPI_ISL_ 1068158 & EPI_ISL_1068221 & EPI_ISL_ 1068262 & EPI_ISL_ 2777401 \\
\hline EPI_ISL_ 1068160 & EPI_ISL_ 1068222 & EPI_ISL_ 1068263 & EPI_ISL_ 2777403 \\
\hline EPI_ISL_1068169 & EPI_ISL_1068225 & EPI_ISL_1068264 & EPI_ISL_2777404 \\
\hline EPI_ISL_1068198 & EPI_ISL_1068248 & EPI_ISL_1068266 & EPI_ISL_2777409 \\
\hline EPI_ISL_1068221 & EPI_ISL_1068249 & EPI_ISL_1068268 & EPI_ISL_2777410 \\
\hline EPI_ISL_ 1068222 & EPI_ISL_1068258 & EPI_ISL_1068269 & EPI_ISL_2777414 \\
\hline EPI_ISL_1068225 & EPI_ISL_1068260 & EPI_ISL_ 1068270 & EPI_ISL_2777415 \\
\hline EPI_ISL_1068226 & EPI_ISL_1068261 & EPI_ISL_1068271 & EPI_ISL_2777465 \\
\hline EPI_ISL_ 1068243 & EPI_ISL_1068262 & EPI_ISL_ 1068272 & EPI_ISL_ 2777466 \\
\hline EPI_ISL_1068248 & EPI_ISL_1068263 & EPI_ISL_1068273 & EPI_ISL_2777467 \\
\hline EPI_ISL_1068249 & EPI_ISL_1068264 & EPI_ISL_1068274 & EPI_ISL_2777469 \\
\hline EPI_ISL_1068258 & EPI_ISL_1068266 & EPI_ISL_1068279 & EPI_ISL_2777470 \\
\hline EPI_ISL_1068260 & EPI_ISL_1068268 & EPI_ISL_1068282 & EPI_ISL_2777472 \\
\hline EPI_ISL_1068261 & EPI_ISL_1068269 & EPI_ISL_1068283 & EPI_ISL_2777473 \\
\hline EPI_ISL_1068262 & EPI_ISL_1068270 & EPI_ISL_1068284 & EPI_ISL_2777474 \\
\hline EPI_ISL_1068263 & EPI_ISL_1068271 & EPI_ISL_ 1068285 & EPI_ISL_2777475 \\
\hline EPI_ISL_1068264 & EPI_ISL_1068272 & EPI_ISL_1068286 & EPI_ISL_2777482 \\
\hline EPI_ISL_1068266 & EPI_ISL_1068273 & EPI_ISL_1068287 & EPI_ISL_2777483 \\
\hline EPI_ISL_1068268 & EPI_ISL_1068274 & EPI_ISL_1068288 & EPI_ISL_2777485 \\
\hline EPI_ISL_1068269 & EPI_ISL_1068275 & EPI_ISL_1068290 & EPI_ISL_2777503 \\
\hline EPI_ISL_ 1068270 & EPI_ISL_1068276 & EPI_ISL_ 1068291 & EPI_ISL_2777508 \\
\hline EPI_ISL_ 1068271 & EPI_ISL_1068278 & EPI_ISL_ 1068292 & EPI_ISL_2777509 \\
\hline EPI_ISL_1068272 & EPI_ISL_1068279 & EPI_ISL_1166615 & EPI_ISL_2777516 \\
\hline EPI_ISL_1068273 & EPI_ISL_1068280 & EPI_ISL_ 1213190 & EPI_ISL_2777599 \\
\hline EPI_ISL_ 1068274 & EPI_ISL_ 1068281 & EPI_ISL_ 1213204 & EPI_ISL_2777698 \\
\hline EPI_ISL_1068275 & EPI_ISL_1068282 & EPI_ISL_ 1261683 & EPI_ISL_2777986 \\
\hline EPI_ISL_1068276 & EPI_ISL_1068283 & EPI_ISL_ 1261685 & EPI_ISL_2777987 \\
\hline EPI_ISL_1068278 & EPI_ISL_1068284 & EPI_ISL_1261690 & EPI_ISL_2777993 \\
\hline EPI_ISL_1068279 & EPI_ISL_1068285 & EPI_ISL_ 1261694 & EPI_ISL_2777999 \\
\hline EPI_ISL_ 1068280 & EPI_ISL_1068286 & EPI_ISL_ 2777236 & EPI_ISL_ 2778002 \\
\hline EPI_ISL_1068281 & EPI_ISL_1068287 & EPI_ISL_2777248 & EPI_ISL_2778004 \\
\hline
\end{tabular}


medRxiv preprint doi: https://doi.org/10.1101/2022.02.04.22270165; this version posted February 6, 2022. The copyright holder for this preprint (which was not certified by peer review) is the author/funder, who has granted medRxiv a license to display the preprint in It is made available under a CC-BY 4.0 International license .

\begin{tabular}{|c|c|c|c|}
\hline EPI_ISL_ 1068282 & EPI_ISL_1068288 & EPI_ISL_ 2777249 & EPI_ISL_2778005 \\
\hline EPI_ISL_1068283 & EPI_ISL_1068289 & EPI_ISL_2777250 & EPI_ISL_833138 \\
\hline EPI_ISL_ 1068284 & EPI_ISL_1068290 & EPI_ISL_ 2777320 & EPI_ISL_833140 \\
\hline EPI_ISL_ 1068285 & EPI_ISL_1068291 & EPI_ISL_2777363 & EPI_ISL_906071 \\
\hline EPI_ISL_1068286 & EPI_ISL_1068292 & EPI_ISL_2777364 & EPI_ISL_918505 \\
\hline EPI_ISL_1068287 & EPI_ISL_1166615 & EPI_ISL_2777373 & EPI_ISL_918506 \\
\hline EPI_ISL_ 1068288 & EPI_ISL_ 1213190 & EPI_ISL_ 2777374 & EPI_ISL_918508 \\
\hline EPI_ISL_ 1068289 & EPI_ISL_ 1213204 & EPI_ISL_2777375 & EPI_ISL_918509 \\
\hline EPI_ISL_1068290 & EPI_ISL_ 1261683 & EPI_ISL_ 2777376 & \\
\hline EPI_ISL_1068291 & EPI_ISL_1261685 & EPI_ISL_2777377 & \\
\hline EPI_ISL_ 1068292 & EPI_ISL_ 1261690 & EPI_ISL_ 2777378 & \\
\hline EPI_ISL_1166615 & EPI_ISL_1261694 & EPI_ISL_2777380 & \\
\hline EPI_ISL_ 1213190 & EPI_ISL_2777236 & EPI_ISL_ 2777383 & \\
\hline EPI_ISL_1213204 & EPI_ISL_2777238 & EPI_ISL_2777384 & \\
\hline EPI_ISL_ 1261683 & EPI_ISL_2777248 & EPI_ISL_ 2777385 & \\
\hline EPI_ISL_1261685 & EPI_ISL_2777249 & EPI_ISL_2777388 & \\
\hline EPI_ISL_ 1261690 & EPI_ISL_2777250 & EPI_ISL_ 2777397 & \\
\hline EPI_ISL_1261694 & EPI_ISL_2777251 & EPI_ISL_2777398 & \\
\hline EPI_ISL_ 2777236 & EPI_ISL_2777320 & EPI_ISL_ 2777399 & \\
\hline EPI_ISL_ 2777238 & EPI_ISL_2777363 & EPI_ISL_2777400 & \\
\hline EPI_ISL_ 2777248 & EPI_ISL_2777364 & EPI_ISL_ 2777401 & \\
\hline EPI_ISL_2777249 & EPI_ISL_2777373 & EPI_ISL_2777402 & \\
\hline EPI_ISL_2777250 & EPI_ISL_2777374 & EPI_ISL_2777403 & \\
\hline EPI_ISL_2777251 & EPI_ISL_2777375 & EPI_ISL_2777404 & \\
\hline EPI_ISL_ 2777320 & EPI_ISL_2777376 & EPI_ISL_2777405 & \\
\hline EPI_ISL_2777363 & EPI_ISL_2777377 & EPI_ISL_2777406 & \\
\hline EPI_ISL_ 2777364 & EPI_ISL_2777378 & EPI_ISL_ 2777407 & \\
\hline EPI_ISL_ 2777373 & EPI_ISL_2777380 & EPI_ISL_2777408 & \\
\hline EPI_ISL_2777374 & EPI_ISL_2777382 & EPI_ISL_2777410 & \\
\hline EPI_ISL_2777375 & EPI_ISL_2777383 & EPI_ISL_2777412 & \\
\hline EPI_ISL_2777376 & EPI_ISL_2777384 & EPI_ISL_2777413 & \\
\hline EPI_ISL_2777377 & EPI_ISL_2777385 & EPI_ISL_2777414 & \\
\hline
\end{tabular}




\begin{tabular}{|c|c|c|c|}
\hline EPI_ISL_2777378 & EPI_ISL_2777388 & EPI_ISL_ 2777415 & \\
\hline EPI_ISL_2777380 & EPI_ISL_2777397 & EPI_ISL_ 2777417 & \\
\hline EPI_ISL_2777382 & EPI_ISL_2777398 & EPI_ISL_ 2777418 & \\
\hline EPI_ISL_2777383 & EPI_ISL_2777399 & EPI_ISL_ 2777419 & \\
\hline EPI_ISL_2777384 & EPI_ISL_2777400 & EPI_ISL_2777454 & \\
\hline EPI_ISL_2777385 & EPI_ISL_2777401 & EPI_ISL_ 2777461 & \\
\hline EPI_ISL_2777388 & EPI_ISL_2777402 & EPI_ISL_ 2777462 & \\
\hline EPI_ISL_2777397 & EPI_ISL_2777403 & EPI_ISL_2777465 & \\
\hline EPI_ISL_2777398 & EPI_ISL_2777404 & EPI_ISL_2777466 & \\
\hline EPI_ISL_2777399 & EPI_ISL_2777405 & EPI_ISL_ 2777467 & \\
\hline EPI_ISL_2777400 & EPI_ISL_2777406 & EPI_ISL_2777469 & \\
\hline EPI_ISL_2777401 & EPI_ISL_ 2777407 & EPI_ISL_ 2777470 & \\
\hline EPI_ISL_2777402 & EPI_ISL_2777408 & EPI_ISL_ 2777472 & \\
\hline EPI_ISL_2777403 & EPI_ISL_2777409 & EPI_ISL_2777473 & \\
\hline EPI_ISL_2777404 & EPI_ISL_2777410 & EPI_ISL_ 2777474 & \\
\hline EPI_ISL_2777405 & EPI_ISL_2777412 & EPI_ISL_ 2777475 & \\
\hline EPI_ISL_2777406 & EPI_ISL_2777413 & EPI_ISL_ 2777477 & \\
\hline EPI_ISL_2777407 & EPI_ISL_2777414 & EPI_ISL_2777478 & \\
\hline EPI_ISL_2777408 & EPI_ISL_2777415 & EPI_ISL_ 2777479 & \\
\hline EPI_ISL_2777409 & EPI_ISL_2777416 & EPI_ISL_ 2777481 & \\
\hline EPI_ISL_2777410 & EPI_ISL_2777417 & EPI_ISL_2777482 & \\
\hline EPI_ISL_2777412 & EPI_ISL_2777418 & EPI_ISL_2777483 & \\
\hline EPI_ISL_2777413 & EPI_ISL_2777419 & EPI_ISL_2777485 & \\
\hline EPI_ISL_2777414 & EPI_ISL_2777420 & EPI_ISL_ 2777495 & \\
\hline EPI_ISL_2777415 & EPI_ISL_ 2777454 & EPI_ISL_ 2777498 & \\
\hline EPI_ISL_2777416 & EPI_ISL_2777460 & EPI_ISL_2777503 & \\
\hline EPI_ISL_2777417 & EPI_ISL_2777461 & EPI_ISL_ 2777507 & \\
\hline EPI_ISL_2777418 & EPI_ISL_2777462 & EPI_ISL_2777508 & \\
\hline EPI_ISL_ 2777419 & EPI_ISL_2777464 & EPI_ISL_ 2777539 & \\
\hline EPI_ISL_2777420 & EPI_ISL_2777466 & EPI_ISL_2777599 & \\
\hline EPI_ISL_2777454 & EPI_ISL_2777467 & EPI_ISL_2777698 & \\
\hline EPI_ISL_2777460 & EPI_ISL_2777468 & EPI_ISL_2777700 & \\
\hline
\end{tabular}


medRxiv preprint doi: https://doi.org/10.1101/2022.02.04.22270165; this version posted February 6, 2022. The copyright holder for this preprint (which was not certified by peer review) is the author/funder, who has granted medRxiv a license to display the preprint in It is made available under a CC-BY 4.0 International license.

\begin{tabular}{|c|c|c|c|}
\hline EPI_ISL_2777461 & EPI_ISL_2777469 & EPI_ISL_2777701 & \\
\hline EPI_ISL_ 2777462 & EPI_ISL_2777470 & EPI_ISL_2777740 & \\
\hline EPI_ISL_2777464 & EPI_ISL_ 2777472 & EPI_ISL_ 2777986 & \\
\hline EPI_ISL_2777465 & EPI_ISL_2777473 & EPI_ISL_2777987 & \\
\hline EPI_ISL_2777466 & EPI_ISL_2777475 & EPI_ISL_2777993 & \\
\hline EPI_ISL_ 2777467 & EPI_ISL_ 2777477 & EPI_ISL_2777995 & \\
\hline EPI_ISL_2777468 & EPI_ISL_2777478 & EPI_ISL_2777996 & \\
\hline EPI_ISL_2777469 & EPI_ISL_2777481 & EPI_ISL_2777997 & \\
\hline EPI_ISL_2777470 & EPI_ISL_2777482 & EPI_ISL_2777998 & \\
\hline EPI_ISL_ 2777471 & EPI_ISL_2777495 & EPI_ISL_2777999 & \\
\hline EPI_ISL_ 2777472 & EPI_ISL_2777498 & EPI_ISL_ 2778000 & \\
\hline EPI_ISL_2777473 & EPI_ISL_2777499 & EPI_ISL_2778002 & \\
\hline EPI_ISL_2777474 & EPI_ISL_2777503 & EPI_ISL_2778005 & \\
\hline EPI_ISL_ 2777475 & EPI_ISL_2777508 & EPI_ISL_811149 & \\
\hline EPI_ISL_2777477 & EPI_ISL_2777516 & EPI_ISL_833136 & \\
\hline EPI_ISL_2777478 & EPI_ISL_2777539 & EPI_ISL_833139 & \\
\hline EPI_ISL_2777479 & EPI_ISL_2777698 & EPI_ISL_833140 & \\
\hline EPI_ISL_ 2777481 & EPI_ISL_2777701 & EPI_ISL_906071 & \\
\hline EPI_ISL_2777482 & EPI_ISL_2777740 & EPI_ISL_906077 & \\
\hline EPI_ISL_2777483 & EPI_ISL_2777986 & EPI_ISL_906081 & \\
\hline EPI_ISL_2777484 & EPI_ISL_2777987 & EPI_ISL_918500 & \\
\hline EPI_ISL_2777485 & EPI_ISL_2777995 & EPI_ISL_918502 & \\
\hline EPI_ISL_ 2777495 & EPI_ISL_2777996 & EPI_ISL_918503 & \\
\hline EPI_ISL_2777498 & EPI_ISL_2777997 & EPI_ISL_918506 & \\
\hline EPI_ISL_2777499 & EPI_ISL_2777998 & EPI_ISL_918508 & \\
\hline EPI_ISL_2777503 & EPI_ISL_2778002 & EPI_ISL_918509 & \\
\hline EPI_ISL_2777507 & EPI_ISL_2778005 & EPI_ISL_ 918511 & \\
\hline EPI_ISL_2777508 & EPI_ISL_811149 & & \\
\hline EPI_ISL_ 2777509 & EPI_ISL_833136 & & \\
\hline EPI_ISL_2777516 & EPI_ISL_833138 & & \\
\hline EPI_ISL_2777539 & EPI_ISL_833139 & & \\
\hline EPI_ISL_2777599 & EPI_ISL_833140 & & \\
\hline
\end{tabular}




\begin{tabular}{|c|c|c|c|}
\hline EPI_ISL_2777698 & EPI_ISL_906071 & & \\
\hline EPI_ISL_ 2777700 & EPI_ISL_906080 & & \\
\hline EPI_ISL_ 2777701 & EPI_ISL_906081 & & \\
\hline EPI_ISL_ 2777740 & EPI_ISL_918500 & & \\
\hline EPI_ISL_2777986 & EPI_ISL_918501 & & \\
\hline EPI_ISL_ 2777987 & EPI_ISL_918502 & & \\
\hline EPI_ISL_2777993 & EPI_ISL_918503 & & \\
\hline EPI_ISL_2777995 & EPI_ISL_918505 & & \\
\hline EPI_ISL_2777996 & EPI_ISL_918506 & & \\
\hline EPI_ISL_ 2777997 & EPI_ISL_918507 & & \\
\hline EPI_ISL_ 2777998 & EPI_ISL_918508 & & \\
\hline EPI_ISL_2777999 & EPI_ISL_918510 & & \\
\hline EPI_ISL_2778000 & EPI_ISL_918511 & & \\
\hline EPI_ISL_ 2778002 & & & \\
\hline EPI_ISL_2778004 & & & \\
\hline EPI_ISL_2778005 & & & \\
\hline EPI_ISL_811149 & & & \\
\hline EPI_ISL_833136 & & & \\
\hline EPI_ISL_833138 & & & \\
\hline EPI_ISL_833139 & & & \\
\hline EPI_ISL_833140 & & & \\
\hline EPI_ISL_906071 & & & \\
\hline EPI_ISL_906075 & & & \\
\hline EPI_ISL_906076 & & & \\
\hline EPI_ISL_906077 & & & \\
\hline EPI_ISL_906080 & & & \\
\hline EPI_ISL_906081 & & & \\
\hline EPI_ISL_918499 & & & \\
\hline EPI_ISL_918500 & & & \\
\hline EPI_ISL_918501 & & & \\
\hline EPI_ISL_918502 & & & \\
\hline EPI_ISL_918503 & & & \\
\hline
\end{tabular}


medRxiv preprint doi: https://doi.org/10.1101/2022.02.04.22270165; this version posted February 6, 2022. The copyright holder for this preprint (which was not certified by peer review) is the author/funder, who has granted medRxiv a license to display the preprint in It is made available under a CC-BY 4.0 International license.

\begin{tabular}{|l|l|l|l|}
\hline EPI_ISL_918504 & & & \\
\hline EPI_ISL_918505 & & & \\
\hline EPI_ISL_918506 & & & \\
\hline EPI_ISL_918507 & & & \\
\hline EPI_ISL_918508 & & & \\
\hline EPI_ISL_918509 & & & \\
\hline EPI_ISL_918510 & & & \\
\hline EPI_ISL_918511 & & & \\
\hline
\end{tabular}

